\title{
Immunoecology of species with alternative reproductive tactics and strategies
}

G. A. LOZANO * $\ddagger \&$ A. F. H. ROS $\dagger, \S$

*Estonian Centre of Evolutionary Ecology, Tartu, Estonia (dr.george.lozano@gmail.com)

† Fischereiforschungsstelle, Langenargen, Germany (afhros@gmail.com)

§ Institut de Biologie, Université de Neuchâtel, Neuchâtel, Switzerland

‡ Present Address: National Institute of Ecology, Republic of Korea 


\section{Abstract}

Alternative reproductive tactics and strategies (ARTS) refer to polymorphic reproductive behaviours in which in addition to the usual two sexes, there are one or more alternative morphs, usually male, that have evolved the ability to circumvent direct intra-sexual competition. Each morph has unique morphological, ecological, developmental, behavioural, life-history, and physiological profiles that shift the balance between reproduction and selfmaintenance, one aspect being immunity. Immunoecological work on species with ARTS, which is the topic of this review, is particularly interesting because the alternative morphs make it possible to separate the effects of sex, per se, from other factors that in other species are inextricably linked with sex. We first summarize the evolution, development and maintenance of ARTS. We then review the main immunoecological hypotheses relevant to species with ARTS, dividing them into physiological, life-history, and ecological hypotheses. In context of these hypotheses, we critically review in detail all immunoecological studies we could find on species with ARTS. Several interesting patterns emerge. Oddly, there is a paucity of studies on insects, despite the many benefits that arise from working with insects: larger sample sizes, simple immune systems, and countless forms of alternative reproductive strategies and tactics. Of all the hypotheses reviewed, the immunocompetence handicap hypothesis and its derivatives have generated the greatest amount of work, but not necessarily the greatest level of understanding. Generally, greater understanding would occur if hypotheses and predictions were always explicitly articulated and several hypotheses with mutually exclusive predictions are addressed simultaneously. Integration has been a one-way street, with ecologists delving deeper into physiology, seemingly at the cost of ignoring their organisms' evolutionary history and ecology. One possible useful framework is to divide ecological and evolutionary factors affecting immunity into those that stimulate the immune system, and those that depress it. Finally, the contributions of genomics to ecology are being increasingly recognized, including in species with ARTS, but we must ensure that evolutionary and ecological hypotheses drive the effort. There is no grandeur in the strict reductionist view of life.

Keywords: alternative reproductive strategies; immunoecology; immunocompetence; sexual selection. 


\section{Introduction}

At its essence, biological variation is categorical (ACGT), but because of the interacting effects of multiple alleles, genes, and environments, it is usually expressed phenotypically as continuous variation. Nevertheless, discrete, non-continuous variation is surprisingly common. For example, 334 instances of plumage polymorphisms occur in birds, in about $3.5 \%$ of all species, distributed across 53 of the 143 families, and 14 of the 23 orders (Galeotti et al., 2003). In insects, wing polymorphisms are common and have been extensively studied (Zera \& Denno, 1997, Roff \& Fairbairn, 1991), and polymorphisms producing distinct castes (O'Donnell, 1996) are one of the best-known characteristics of eusocial insects. Of all the types of discontinuous variation, morphological variation is perhaps the most readily evident, but it is usually associated with physiologically mediated discontinuous variation in behaviour. For example, insects' wing polymorphisms (Roff \& Fairbairn, 1991) are mediated by juvenile hormone (Dingle \& Winchell, 1997), and associated with dispersal polymorphisms (Zera \& Denno, 1997). A wide assortment of other such polymorphic behaviours exist, for example, in chemosensory recognition (López et al., 2009), foraging (Ehlinger \& Wilson, 1988), fighting (Crespi, 1986) and in reproduction (Oliveira et al. 2008b). In this review, we examine immunity in species with a specific type of polymorphic reproductive behaviours.

Alternative reproductive tactics and strategies (ARTS) refer to polymorphic reproductive behaviours in which in addition to the usual two sexes, there are one or more alternative morphs, usually male, that have evolved the ability to circumvent direct intrasexual competition. Unfortunately, the ARTS literature has become a definitional quandary because as it developed, it relied on colloquial terms that were given additional and special meanings. Semantically, "strategies" are simply long-term "tactics", and "tactics" are nothing more than short-term "strategies", big picture versus detailed plans, relatively immutable versus highly variable. In the evolutionary ecology literature, the term "strategy" was initially used to refer to variation resulting from genetic effects, and the term "tactic" to variation resulting from environmental factors (Alcock, 1979, Maynard-Smith, 1982). This nomenclature carries with it the implicit assumption that genetic effects are permanent and environmental effects are ephemeral. Although this way of thinking is outdated and unnecessary (Brockmann, 2001, Oliveira et al., 2008a), the association still exists in the literature and in people's minds.

Similarly, some authors use the term "polymorphic reproductive behaviours" synonymously with "alternative reproductive behaviours" (reviewed by Oliveira et al., 2008b). 
However, the term "polymorphic" is more general, literally only implying the existence of more than one form. In contrast, the adjective "alternative" implies that all options are not equal, and that some of them are not the conventional or mainstream options, as in "alternative lifestyle" or "alternative music". In this sense, the term "alternative reproductive behaviour" actually refers to reproductive behaviour that is absent in phylogenetically or ecologically related species, which only have the "normal" behaviour. For example, in the halictid bee Lasioglossum erythrurumoccur (Kukuk \& Schwarz, 1988, Houston, 1970) and the andrenid bee Perdita portalis (Danforth \& Neff, 1992, Danforth, 1991), "normal” males leave the nest in search of mates, as in related species, but in both species there are also "alternative" males. These are large and flightless males that do not leave the nest but instead fight for access to females within the nest. ARTS were recognized and described in many species before they were conceptually unified. Therefore, a variety of names have been used, such as independent and satellites, fighters and scramblers, fighters and sneakers, bourgeois and kleptogamic, phallic and aphallic, bourgeois and parasitic, $\mathrm{M}+$ and $\mathrm{M}-$, producers and scroungers, etc., but in many respects, these terms are functionally equivalent.

Several authors have tried to clarify this nomenclature (Brockmann, 2001, Caro \& Bateson, 1986, Oliveira et al., 2008a), evidently to no avail, probably because of the pervasiveness of the colloquial sense of the co-opted words, the need for continuity, and, as always, intellectual inertia. Instead of immersing ourselves into this debate, we will just explicitly define the terms we use and the scope of this review. First, we use the term "alternative reproductive behaviours" to mean a specific type of polymorphic reproductive behaviours in which there is a conventional, "normal" reproductive behaviour, and one or more alternatives. The "normal" behaviour is found in related species in which the "alternative" does not exist. The alternative has been referred to as the "disfavoured role" (Uglem et al., 2001), but it does not have to be so. The alternative might actually be the main or primary reproductive behaviour in a species (Almada \& Robalo, 2008). For example, in the fallfish minnow (Semotilus corporalis), less than 10\% of mature males are territorial and the rest as sneakers (Ross, 1983). Second, we will not place any limitations on the underlying mechanisms, but we shall distinguish whether the reproductive behaviours and morphs are fixed for the individual's entire lifetime, or plastic (i.e., flexible), when individuals change from one to another. If plastic, we will make the distinction of whether the change occurs only once, at a carefully chosen time in their lives, or whether the change(s) is/are reversible (Moore et al., 1998, Oliveira et al., 2008a, Moore, 1991). In most cases, we will be addressing 
cases in which these alternative reproductive behaviours are relatively long-term, at least sufficiently so to affect immunity, but to avoid the dilemma of when exactly a tactic becomes a strategy and vice-versa, we shall use the more inclusive term "alternative reproductive tactics and strategies" (ARTS).

In species with ARTS, each morph has unique morphological, ecological, developmental, behavioural, life-history, and physiological profiles that shift the balance between reproduction and self-maintenance, one aspect being immunity. Here, we review the immunoecology of species with alternative reproductive tactics and strategies. Several ultimate and ecologically-based proximate hypotheses, discussed in detail below, predict that immune function differs between males and females, and by extension among morphs in species with ARTS. Species with ARTS are particularly interesting because they have at least one more additional life-history pathway that is not present in other species. These alternative reproductive pathways require a new set of central and peripheral adaptations that in other species are inextricably linked with each sex. Immunoecological work on species with ARTS, which is the topic of this review, is particularly interesting because the alternative morphs make it possible to separate the effects of sex, per se, from other factors that in other species are inextricably linked with sex. Hence, species with ARTS offer an opportunity to explore how immunity evolved in synergy with additional combinations of reproductive traits in each sex and within a sex (Noble et al., 2013).

First, we briefly review the evolution, maintenance, and development of ARTS, relying mostly on several excellent reviews (Brockmann, 2001, Oliveira et al., 2008a, Taborsky et al., 2008) and focusing primarily on areas specifically relevant to immunoecology. Second, we examine the main hypotheses in immunoecology that deal with differences between the sexes, hypotheses that could be tested more explicitly and extensively using species with ARTS. Third, we review in detail immunoecological work on species with ARTS, specifically relating it to the aforementioned hypotheses. Finally, we offer prospects for future work, both for researchers already working with species with ARTS, researchers working on immunoecology, and of course, to guide our own future endeavours.

\section{Evolution, maintenance, and development of arts}

We include a brief summary of the evolution, development and maintenance of ARTS. This section should not be considered a comprehensive review; several are readily available 
(Taborsky \& Brockmann, 2010, Oliveira et al., 2008b, Gross, 1991, Tabosrky, 2001). The purpose here is merely to establish some common ground to facilitate the ensuing discussion.

\section{Origin and maintenance of ARTS}

The stage is set up for the evolution or ARTS when a high population density coupled with intense intrasexual selection allow only the largest and strongest males to obtain most of the copulations (Kokko \& Rankin, 2006). Interactions among males might include territorial defence, direct confrontations, and extended and/or elaborate sexual displays. In such situations, males are selected to divert resources towards growth and, given that small males are unable to reproduce, perhaps even to delay sexual maturity. On the other hand, this scenario also favours adaptations that allow males to reproduce while avoiding this intense competition. Contrary to popular belief, males seldom "want a challenge" when it comes to mating. They (we) are usually quite willing to mate opportunistically, without having to search for females, compete with other males, establish and defend territories, court females, or pay any of the costs associated with reproduction. ARTS are nothing more than long-term, sometimes permanent, behaviourally and often morphologically distinct phenotypes specializing in opportunistic, low-cost mating. Because these specializations are relatively long-term to permanent, ARTS have evolved along with a wide range of similarly long-term to permanent behavioural, morphological, and physiological adaptations.

We usually observe the result of evolution but seldom do we have the privilege of witnessing evolution in action. When ARTS first begin to evolve in a population, avoiding intra-sexual competition is only half the battle. Before the alternative male phenotype is established, females are under strong selection to avoid mating with small, subordinate males. Hence, for "alternative" males to be successful, they must not only avoid direct competition with "normal" males, but also bypass female choice. In many cases, they do both via sneak copulations. However, once the alternative morph is established, females would no longer be selected to avoid these males; in fact, the loci for male morph and female preference for that morph would be linked (Wellenreuther et al., 2014). Thereafter, female preference for the alternative morph might fluctuate, depending on the morph proportions and their relative reproductive success. A final requirement is disruptive selection, whereby intermediate males are disfavoured, both because of female avoidance (Cummings \& Ramsey, 2015) and because of their inability to compete with either of the two other types of males (Fig. 1). 


\section{Frequency and Reproductive Success}

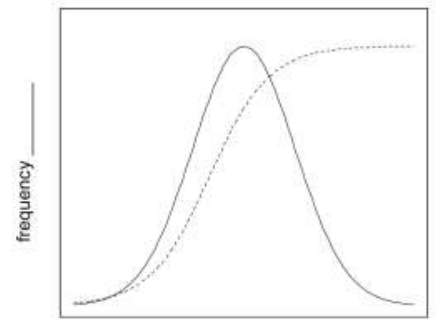

size

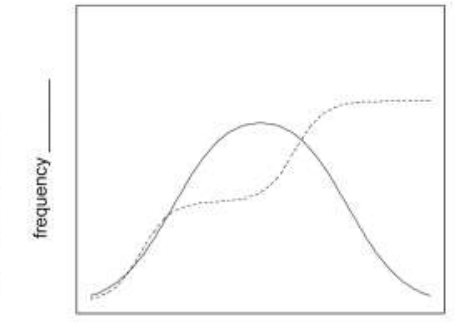

size

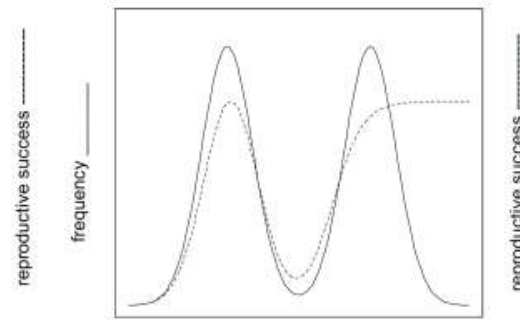

size

Fig. 1.- Frequency and reproductive success of "normal" and "alternative" males during the evolution and establishment of ARTS in a population. "Size" is used in the x-axis, but it could also be any other aspect of behaviour or morphology that is important in mating. In the start, there is only one morph with a highly skewed distribution in reproductive success. In the third graph, the final relative frequencies of the 2 morphs might vary depending on the equilibrium that is eventually reached.

In species with ARTS, each morph takes a different approach to obtaining copulations, so antagonistic selection (Holland \& Rice, 1998) does not occur just between two sexes, but also separately between each morphs. In due time, through condition-dependent and pleiotropic effects, genetic correlations develop between traits, whether or not these traits are functionally related (Kupper et al., 2016, Lawson et al., 2011). These sets of traits and their interrelationships often have a long evolutionary history, and striking examples occur in sexual dimorphic sets of behavioural and morphological traits (Wellenreuther et al., 2014, Lande, 1980, Barron et al., 2015). Furthermore, intra-locus sexual conflict, whereby different optima for each sex exist within a locus, is extended to include intra-locus conflict for different morphs within one sex (Morris et al., 2013, Bielak et al., 2014).

On an evolutionary time scale, ARTS are relatively ephemeral; they do not become permanent features of relatively large clades. For example, a phylogenetic analysis of blennies, wrasses, and salmonids indicates that ARTS evolved independently in several lineages, but they also readily disappeared (Almada \& Robalo, 2008). In the side-blotched lizard, (Uta stansburiana), described in more detail below, there are 3 male morphs. The proportion of these 3 morphs varies geographically, and all morphs are not present in all populations. Territorial morphs can continue to function without sneakers, but sneakers cannot function in the absence of territorials. So whenever one of the morphs is absent, it is always the sneaker morph. When sneakers are lost in a population, allelic frequencies shift, which causes rapid 
morphological divergence, and leads to distinct populations, or even sub-species (Corl et al., 2010). It has been suggested that the disappearance of polymorphisms is one possible mechanism of speciation (West-Eberhard, 1986).

Whether permanently or not, the maintenance of ARTS can be considered in the same context as, or as an extension of, sex allocation theory (Fisher, 1930, Darwin, 1871, Charnov, 1982). Essentially, a negative frequency-dependent system is set-up whereby the alternatives accrue differential benefits that depend on each other's frequency in the population and/or their respective fitness. Costs and benefits of each morph depend on population dynamics, such as the changes in the density and proportion of morphs in a population. Genetic variation between and within morphs might code for developmental pathways leading to ARTS, and for responses to environmental variation that specifically take into account morph proportions. In both cases, ARTS might be selected against when the balance between costs and benefits gets tipped in favour of a single phenotype. Therefore, to understand the maintenance of ARTS, it is important to study not only the genetics, but also the costs and benefits of the associated traits (Oliveira et al., 2008a)

\section{Development of morphs}

Morphs develop via a variety of hormonal mechanisms, depending on the species (Rhen \& Crews, 2002). ARTS can be fixed or flexible; if flexible, they can be reversible or not. These options evolve depending on the mating opportunities, and the costs and benefits involved in switching back and forth. The benefit of fixed morphs is that they can be more specialized, behaviourally, morphologically, and physiologically, and that specialization can begin to take shape as soon as the individual chooses one developmental path over another. The drawback of a fixed morph is the loss of opportunities, which may be particularly important when mating opportunities vary widely spatially or temporally. For the same reason, reversible choices are more likely to occur in adults and take place relatively quickly, in a matter of days, whereas and non-reversible choices occur more often at an earlier developmental stage and their development takes relatively longer (Emlen, 2008).

Whether they are reversible or not, when morph changes are plastic, they develop via threshold mechanisms. These mechanisms entail monitoring the environment, biotic and abiotic factors, particularly the density and frequency of conspecific morphs, and comparing that against some internal threshold to choose whether to initiate the change. All aspects of the process are regulated by hormones. The rate of hormone synthesis, secretion, and degradation, and the expression, production, and binding affinities of receptors all vary and 
are under selection (Emlen, 2008). In insects, these changes are usually regulated by juvenile hormone (Brockmann, 2008), and in vertebrates by sex steroids. One-time changes are more both onerous and carry more long-term consequences than reversible changes, hence they are probably under stronger selection. The burden is even higher when the morphs are fixed. In the few cases in which morph determination is strictly genetic, peripheral adaptations can begin to develop as early as possible. In fact, genes associated with a given morph are expected to be linked.

In vertebrates, hormonal control of sexual development traits is usually separated into organizational effects, which occur early in development, and activation effects, which occur during adulthood (Phoenix et al., 1959). For example, the sexual differentiation of the brain and genitalia, which begin before birth, are organizational events, whereas changes in behaviour and morphology that occur every breeding season are activational events. One exception is puberty, which is considered to be a period of both re-organization and activation (Romeo, 2003). This paradigm has been extended to the development of morphs in species with ARTS (Moore, 1991), the suggestion being that regulation is relatively more important in species with fixed morphs, and activation relatively more important in species with plastic morphs. However, a survey of the literature fails to find support for this hypothesis (Oliveira et al., 2008a). A thorough analysis indicates that the situation is complex: depending on the species, several biochemically related androgens are involved in the development of ARTS, in different proportions and with different effects. One generalization that does arise is that androgens are more important in the development of morphological ARTS than in the development of strictly behavioural ARTS (Oliveira et al., 2008a).

Finally, in the standard vertebrate, sex hormones released by the gonads not only regulate reproduction but also morphology and behaviour. In species with ARTS, the "alternative" morphs produce gametes and sex hormones regulate gametogenesis, just as they do in "normal males, but morphology and behaviour are regulated independently for each morph. Therefore, it is important not only to examine the production, release and distribution of various hormones, but also their effects on target tissues.

\section{Immunoecological hypotheses relevant to species with ARTS}

The immune system protects animals against parasites. Parasites are defined here broadly and functionally to include organisms that live in or on a heterospecific animal, the host, obtain nutrients primarily from the host, and have the potential to decrease its fitness (Lozano, 1998). 


\section{G. A. LOZANO \& A. F. H. ROS 10}

Like all other physiological processes, immune function carries an energetic cost. This cost has been confirmed by direct energetic measures (e.g., Barr et al., 1922, Demas et al., 1997, Muehlenbein et al., 2010) and by examining trade-offs between immune function and other energy-demanding processes (e.g., Allander \& Bennett, 1995, Marais et al., 2011, Xu \& Wang, 2010). This concept of trade-offs is pivotal to the study of immunity in an evolutionary ecology context. In most respects, this trade-off is the general premise of several hypotheses detailed below that have been tested in species with ARTS. This section presents these hypotheses and their predictions, but should not be considered an exhaustive review of these hypotheses. Nor should readers assume that only these hypotheses can be tested in species with ARTS. The hypotheses are arbitrarily divided into physiological, life history, and ecological hypotheses, all of which overlap.

\section{PHYSIOLOGICAL}

\section{Immunocompetence handicap hypothesis (ICHH)}

The ICHH posits that honesty in vertebrate sexual signals is maintained because testosterone, the hormone that causes the development of sexual signals in males, has the unfortunate side effect of also depressing immune function (Folstad \& Karter, 1992). Hence, a trade-off between display and immune protection is expected, and males who can afford to depress their immunity are better able develop more prominent sexual displays. The honesty of these sexual signals (sensu Zahavi, 1975) is guaranteed by their immunological cost. Although only testosterone and only males were mentioned in the original hypothesis, in its general form, the hypothesis also applies to several other androgens, and to females to the extent that they are exposed to androgens.

Tests of the ICHH have been correlational and experimental. Correlationally, males should be immunosuppressed relative to females, more so at times of testosterone peaks during their breeding cycles. Experimentally, exposure to testosterone should enhance sexual traits in males and decrease immune function. Conversely, an experimental decrease in testosterone should depress the development of sexual traits and improve immune function. Of course, the timing of this manipulation is important. Depending on the species, on would have to consider the timing of the development of seasonal sexual traits, and the timing of the breeding season itself. Nevertheless, in both instances of experimental exposure to testosterone, organisms would be moved away from their individual optima, and regardless of the effects on immunity or sexual signals, this imposed change should have an overall 
negative effect on fitness. In general, studies fail to find support for the key prediction that testosterone depresses immunity (reviewed by Roberts et al., 2004, Nunn et al., 2009).

In the $\mathrm{ICHH}$, the exact nature of the link between immunity and sexual traits depends on the specific effects of testosterone. The hypothesis was based on the physiological effects of testosterone, but did not incorporate the mechanisms behind these effects. One possibility is that testosterone explicitly depresses specific aspects of immunity, perhaps then secondarily liberating resources for other functions, including sexual displays. Another not necessarily mutually exclusive mechanism is that testosterone forces the development of sexual displays, in the process using up resources and energy that would otherwise be allocated towards other biological functions, including immunity (Wedekind \& Folstad, 1994).

Using testosterone-exposed females, the two alternatives could be tested. One option predicts that immune function should decrease upon experimental exposure to testosterone; the other option predicts that immune function would decrease only if testosterone-exposed females develop male-like sexual ornaments or engage in costly male-like behaviours. Of course, exposing females to unnatural levels of male hormones might have unknown and undetected consequences that would make interpretation difficult. In contrast, using species with ARTS it is possible to compare immune function among different types of males, each with its distinct hormonal profile (Ketterson \& Nolan, 1999).

The ICHH's predictions differ depending on the presence of testosterone, its distribution over the animal's body, and the sensitivity to it of various body tissues. For example, in female mimicking morphs, spermatogenesis still depends on testosterone, but circulating levels might differ from those of "normal" males, and various tissues or organs might be differentially sensitive to its effects. Hence, in species with ARTS, it is possible to separate the direct effects of testosterone per se on immunity, from the indirect effects caused by a reallocation of resources towards sexual displays.

Similarly, the ICHH generates different predictions in species with ARTS in which the morphs are reversible versus species in which the morphs are permanent. In the first case one would expect to see fluctuations in androgens and immunity that reflect a more cautious approach, only a partial commitment to a given morph. In contrast, individuals have more at stake when the change is permanent, and as a terminal gambit, final stage males might expose themselves to high levels of androgens, and be more willing to suppress their immunity to allocate more resources towards reproduction.

A related and supposedly competing hypothesis has also been proposed: the “immunodistribution hypothesis" (Braude et al., 1999). One way immunocompetence can be 


\section{G. A. LOZANO \& A. F. H. ROS 12}

measured is by counting various immune cell types present in the blood. This hypothesis argues that these measures might give spurious results because testosterone might not actually decrease the numbers of any specific cell type, but rather merely redistribute these cells throughout the body, and this redistribution might then be mistakenly interpreted as immunosuppression (Braude et al., 1999). However, the immunodistribution hypothesis does not specify what happens to these cells after they are no longer circulating, and nor the extent to which different cell types are necessary in the blood stream as opposed to other tissues. Hence, this hypothesis seems to be more of a critique of a specific method of assessing immunocompetence, whether or not testosterone is involved, than an alternative to the ICHH.

The opposite mechanism, that immune activation depresses testosterone, has also been proposed (Boonekamp et al., 2008), and it also predicts that only healthiest males should develop the most elaborate secondary sexual traits (Table 1). This mechanistic hypothesis differs from the ICHH only in the directionality of the effect; the ICHH says that testosterone affects immunity, and this one says that immune activation lowers testosterone. However, this distinction yields different predictions and different implications about the meaning of sexual signals to females. In many cases, both hypotheses could be tested simultaneously within the same study.

\section{"Sperm protection" hypothesis}

Another testosterone-based hypothesis, the sperm protection hypothesis, states that testosterone suppresses immunity because spermatocytes are haploid and recognized as "foreign" by the immune system (Hillgarth et al., 1997). Spermatocytes are located within one of several immunoprivileged areas in the body (Streilein, 1996), where they are physically isolated from direct contact with blood. Nevertheless, some lymphocytes might squeeze through the testes-blood barrier, and spermatocyte antigens might escape and enter circulation. The suggestion is that to prevent the attack of sperm cells, testosterone, in addition to inducing spermatogenesis, also causes a local suppression of immunity. Furthermore, the hypothesis argues, testosterone also causes immunosuppression elsewhere in the body when it either spills over or when it is necessary for purposes other than spermatogenesis. 
Table 1.- Contrasting predictions about the relationship between sexual signals and immunity, depending on whether testosterone lowers immune function (Folstad \& Karter, 1992), or the reverse mechanism, that immune activation lowers testosterone (Boonekamp et al., 2008).

\section{Experimental Treatment}

Increase in $\mathrm{T}$
T lowers immunity

(1) Decreased immunity.

2) More elaborate sexual traits.

(1) No effect on T.

(2) Decreased sexual traits-

due to energetic

requirements.

Information gleaned from sexual traits
Willingness to increase $\mathrm{T}$ and Low exposure to parasites at risk disease at the time sexual the time sexual traits traits developed. developed.
Immunity lowers $T$

(1) No direct effect on

immunity.

(2) More elaborate sexual traits.

(3) If resources are lacking, a decrease in all other energy requiring functions, not just immunity.

(1) Decrease in T.

(2) Decreased sexual traitsdue to energetic requirements and lower $\mathrm{T}$. 


\section{G. A. LOZANO \& A. F. H. ROS 14}

Few explicit test of this hypothesis exist, but a meta-analysis of 32 studies in which corticosteroids were used to treat infertility in men showed that corticosteroid reduced plasma and seminal anti-sperm antibodies, increased sperm count and motility, and ultimately increased pregnancy rates (Skau \& Folstad, 2005). Other than the predicted effect of testosterone specifically on areas near the testes, the predictions of this hypothesis do not differ from those of the ICHH. Both hypotheses argue that testosterone is necessary for the development of secondary sexual traits, and is also immunosuppressive, so a trade-off occurs and hence, sexual signals are guaranteed to be honest. The sperm protection hypothesis, however, does provide a functional reason as to why testosterone lowers immunity.

Although this hypothesis has not received much detailed attention, it might be particularly applicable to species with ARTS. One general prediction is that animals with large and prolific testes would be relatively immuno-suppressed. In several species with ARTS, one male morph (dominant, large, pugnacious, and/or territory holders) displays the typical somatic effects of testosterone, and the other morph (small, sneakers, non-territorial, and/or female mimics) sometimes has disproportionably large testes. Hence, correcting for the differences in somatic and gonadal sensitivity of testosterone, and the relative effectiveness of the respective blood-testes barriers, it might be possible to test whether immune function decreases because of a spill-over of testosterone, or because of a reallocations of resources towards growth.

\section{LIFE HISTORY}

\section{Bateman's Principle}

A limitation of the ICHH and its derivatives is that they apply only to species in which sexual ornaments depend on testosterone, namely vertebrates. However, sex differences in immunocompetence should also be expected simply based on life history (Rolff, 2002). Variance in reproductive success is usually greater for males, and generally males maximize their reproductive success by mating with more females, whereas females do so by increasing their fecundity by having longer reproductive lifespans (Bateman, 1948). Hence, life history predicts that investment in immune function ought to be greater and less variable for females than for males. More generally, extending the logic to species with ARTS, the expectations are that the sex, gender, or morph with greater lifetime variance in reproductive success should have a more risky lifetime strategy and hence investment on immune function should be lower and more variable. 
A strict life-history hypothesis would still be viable in the absence of a testosteronemediated system. The rationale does not depend on the mechanism regulating the trade-off, so it is applicable to non-vertebrate taxa, and even non-animal taxa. Non-animal taxa might not have an immune system per se, but still invest on pathogen defence. Another important difference is that form a life history perspective, sex differences in immunity are expected before the onset of reproduction and would work and even in the absence of costly sexual ornaments in males. The moment sexes or morphs are determined, investment in immune function would start to follow different paths.

\section{ECOLOGICAL}

\section{Energy and resource constraints}

The basic premise of life-history theory is the fact that resources are limited and organisms must face choices in the allocation of resources towards various functions (Pianka \& Parker, 1975, Williams, 1966, Roff, 2002, Stearns, 1992). All physiological processes carry an energetic cost. Hence, everything else being equal, additional energetic requirements, such as sexual displays, reproduction, thermoregulation, territorial defence, or parental effort, might reduce investment in immunity. A wide variety of trade-offs involving immune functions have been examined. For example, eliciting an immune response increases energetic costs (Marais et al., 2011); fasting suppresses immune responses (Xu \& Wang, 2010); thermal stress depresses immunity (Dabbert et al., 1997), and higher reproductive effort decreases long term immune function (Ardia et al., 2003). Countless other examples exist.

However, finding the expected negative relationship between two resource- or energyrequiring functions is not particularly enlightening. Given limited resources, such dual tradeoffs are a physical necessity. A more interesting scenario emerges when more than 2 players or energy-requiring functions are examined concurrently. For example, like any other animal, a reproducing female is expected to avoid parasites (Hart, 1990). However, when a third party is involved, her offspring, and given that antibodies are transferred to offspring (Hasselquist \& Nilsson, 2009), she could also benefit by mithridatically ${ }^{1}$ (Mayor, 2009) exposing herself to parasites, developing immunity, and transferring that immunity to her offspring (Lozano \& Ydenberg, 2002). Similarly, when morphs are involved, not just 2 sexes, the behavioural, ecological, and evolutionary options become more interesting. Some male morphs might

\footnotetext{
${ }^{1}$ After Mithridates VI (135 - 63 B.C.), King of Pontus (113 - 63 B.C.), who, legend has it, purposely exposed himself to poisons in an attempt to become immune to them (Mayor 2009).
} 


\section{G. A. LOZANO \& A. F. H. ROS 16}

spend energy providing paternal care, developing sexual signals that also attract predators, or constructing structures for mate attraction and brood care (Andersson, 1994). In species with ARTS, "alternative" males pay only some of the costs that "normal" males pay, so these species offer more appropriate systems in which to further test these trade-offs.

\section{Exposure Risk}

Behavioural defences against parasites come in many forms, including, for example, the physical removal of parasites (Murray, 1987, Grutter, 1996), prophylactic or therapeutic selfmedication (Villalba et al., 2010, Lozano, 1998), and the avoidance of certain habitats (Piersma, 1997), food items (Fleurance et al., 2007, Keymer et al., 1983), or individuals (Thomas et al., 1996, Ramnath, 2009).

Similarly, immune defences can also vary depending on the habitat (Ardia, 2005, Lindström et al., 2004), and the expected level of parasite exposure (Joop \& Rolff, 2004). Seasonal changes in immune function (Nelson, 2004) suggest that animals can pre-emptively adjust their immune systems in anticipation to parasite exposure (O'Neal, 2013). Hence, differences between the sexes, or morphs, might exist even in the absence of any of the effects proposed by the aforementioned hypotheses. Given differences in behaviour, whether they are differences in foraging, migration, mate searching, mating, parental care, etc., morphs might be differentially exposed to parasites and would be expected to invest on their immunity accordingly.

\section{Immunoecology in species with ARTS}

\section{Amphibians}

Because of differences in mate attraction cues, sound or chemicals, fertilization modes, external or internal, and development habitats, aquatic and terrestrial, amphibians have evolved the widest assortment of reproductive modes among vertebrates (Haddad \& Prado, 2005). Because the immune system of immature amphibians is not as reliable as that of adults, and most amphibian parasites infect their hosts and reproduce during their hosts' aquatic stage, it has been suggested that parasites area a strong selective pressure for the evolution of the variety of reproductive strategies that occur in amphibians (Todd, 2007). However, ARTS in amphibians consist only of conditional short-term changes in behaviour, in which individuals change between alternatives relatively quickly, in a time scale ranging from a few minutes to entire breeding seasons (Zamudio \& Chan, 2008). Because most ARTS in amphibians are ephemeral, they have not been studied in relation to changes in immune function. 


\section{Fish}

Among vertebrates, ARTS are particularly prominent in fish because of several reasons. First, external fertilization is the norm in fish, which makes it more difficult for males to control access to females, and for females to enforce their partner choice. Both these factors facilitate the evolution of sneakers. Second, fish often have indeterminate growth, so in some cases adult males have to compete with males several times their own size, which favours the evolution of reproductive tactics and strategies that do not rely on direct competition. Third, flexible and variable sex-determination mechanisms allow for the evolution of several age-, size- and condition-dependent ARTS, with some fish able to change their sex and male morph back and forth. Finally, in fish, when parental care occurs, it is more likely to be paternal, not maternal or bi-parental, a condition that favours the evolution of parasitic males that exploit other males' paternal care. Hence, the variety and complexity of ARTS among fish is unlike that of other vertebrate classes (Taborsky, 1994, Taborsky, 2008, Garant et al., 2003, Tabosrky, 2001, Fleming, 1996), but surprisingly, their immunoecology has only been examined in a handful of species.

The Arctic char (Salvelinus alpinus) is a circumpolar Salmonid that breeds in fresh water. Their life histories are quite variable. They can be either landlocked or anadromous. Their final adult size ranges from 13 to $75 \mathrm{~cm}$, and the age of maturity from 3.5 to 10 years (Vøllestad \& L'Abée-Lund, 1994). During the breeding season, both sexes display carotenoiddependent red coloration in their abdomens (Scalia et al., 1989). Depending on their relative size in their respective populations, males use one of two mating tactics: guarding or sneaking. Females are aggressive towards small sneakers, which could be interpreted as a preference for larger males, or a defence against nest predation. In addition, some populations have a dwarf male morph that is exclusively a sneaker (Sigurjónsdóttir \& Gunnarsson, 1989). Compared to dominant males, subordinate males have relatively smaller testes but higher sperm density and sperm number relative to their testes size (Liljedal \& Folstad, 2003). Morphological differences can be induced as a dominance hierarchy is established in just a few days (Liljedal $\&$ Folstad, 2003), so these morphs are at the extreme of the ephemeral-permanent spectrum.

Måsvær et al. (2004) conducted a correlational study that did not specifically address differences among morphs. Incidence and intensity of infection of several parasites were combined via Principal Component Analysis. The first 2 principal components correlated with sperm mass and density. However, the PC loadings are not shown, so it is not possible to know whether the relation between parasites and sperm is positive or negative. Nevertheless, 


\section{G. A. LOZANO \& A. F. H. ROS 18}

no relation was found between immune measures (granulocytes, lymphocytes and spleen mass) and testes size, sperm number or secondary sexual traits.

Liljedal \& Folstad (2003) placed males into pairs, and a social hierarchy was established in just 4 days. Although subordinates were significantly more stressed, but there were no differences in immune function, as measured by circulating granulocyte and lymphocyte counts. Hence, neither stress nor dominance status affected immune condition. It might be interesting to repeat or expand this work on Arctic char, paying particular attention to morph differences and using experimental infections and more sophisticated immunological techniques.

Immunity and alternative reproductive tactics have been studied in two species of blennies: The Azorean rock-pool blenny (Parablennius parvicornis), and the peacock blenny (Salaria pavo). Both species have sequential polymorphism associated with changes in reproductive behaviour (Oliveira et al., 2001, Santos, 1985a). Small young males without secondary sexual characters (M- morph) reproduce as a sneakers/parasites, and older and larger males develop secondary sexual traits $(\mathrm{M}+\mathrm{morph})$ and follow the bourgeois tactic, either as nest holders or non-territorial floaters (Santos \& Almada, 1988, Ruchon et al., 1995). The switch is not reversible.

The Azorean rock-pool blenny (total length $8-18 \mathrm{~cm}$ ) inhabits shallow waters on the Atlantic coast of North-East Africa and its adjacent Islands. The best studied population inhabits intertidal pools on Faial, in the Azores. The pools contain crevices that give the fish shelter from most predators. In the spring, large $\mathrm{M}+$ males compete aggressively for these natural cavities (Santos, 1985b). Males that manage to defend and clean out a cavity become darker and start courting females (Santos \& Barreiros, 1993). Females enter the pools at high tide and visit several nest-holding males to lay their eggs. The smaller M- males sneak into the nest when nest-holder males $(\mathrm{M}+)$ are inattentive. On the other hand, larger $\mathrm{M}$ - males settle close to a nest as "satellites", and provide a service to nest holders $(\mathrm{M}+)$ by keeping sneakers (smaller M- males) at bay. Nest-holder males $(\mathrm{M}+)$ habituate to the presence of these satellite males, but the satellites also fertilize eggs by sneaking. About $30 \%$ of Azorean rockpool blenny males are M- (Fig. 3 of Santos, 1995) and most males switch to the M+ morph when they are 2 or 3 years of age (Oliveira et al., 2005),

The peacock blenny (total length $5-15 \mathrm{~cm}$ ) breeds in crevices and holes in hard substrate of intertidal areas in the Mediterranean and adjacent Atlantic coast. The best studied population is on Culatra Island in Portugal, where nest-holding males have populated holes in stones and debris that are used to border clam cultures belonging to local fisherman. Nest- 
holding males $(\mathrm{M}+)$ have a conspicuous orange crest and have anal glands. The anal gland produces mate-attracting pheromones and antibacterial compounds that promote egg survival (Pizzolon et al., 2010). Females and parasitic males (M-) are smaller than nest holding males; M- males are female mimics in appearance and behaviour (Gonçalves et al., 2005). The age and size at which M- switch to M+ depends on the availability of suitable nest sites, and when nest sites are abundant, M- males are rarer (Saraiva et al., 2010). At the peak of the reproductive period, 11 to $43 \%$ (mean 25\%) of males are M- (Fagundes, pers.obs.). Females visit several males and prefer to lay their eggs in nests that already have large broods (Ros \& Oliveira, 2009)

Ros et al. (2006a) tested the ICHH in rock-pool blennies correlationally by measuring circulating androgens, lymphocyte ratios and primary antibody responses. Both 11ketotestosterone and testosterone were higher in $\mathrm{M}+$ males than in $\mathrm{M}$ - males and lymphocyte numbers and humoral immunity were lower in $\mathrm{M}+$ males than in $\mathrm{M}-$ males. However, within each morph, there was no relation between androgens and immunocompetence. Hence, the first result supports the ICHH but the second does not. They suggested that either the hypothesis was incorrect, or that changes in androgens are not necessarily reflected immediately by changes in immunocompetence. Furthermore, they found that in $\mathrm{M}+$ males androgens decreased after an immune challenge (Ros et al., 2006a), which provides some support for the aforementioned "reverse" ICHH.

On the other hand, Ros et al. (2006b) conducted an experimental study in which androgens were manipulated and provided partial support for the ICHH. In this study, 11ketotestosterone, but not testosterone, induced the development of secondary sexual characters in M- males. Furthermore, M- males treated with 11-ketotestosterone swam less than controls. Finally, lymphocytes numbers decreased in testosterone treated males relative to controls, but not in the 11-ketotestosterone group. Hence, the ICHH seems to be too general for the peacock blenny; the androgen that affects morphology and behaviour differs from the androgen that affects immunity. These 2 androgens, 11-ketotestosterone and testosterone, are separated by only one metabolic step. There are no evolutionary or ecological hypotheses of why they have such different effects, or, for that matter, those particular effects. It is unknown whether these differences hold for other species, but this problem might prove to be a fruitful area of research for both ecologists and physiologists.

An energetic constraint explanation is also possible. During the breeding season, nestholders $(\mathrm{M}+)$ spend a lot of resources and time developing secondary sexual traits, defending territories courting females, and cleaning and aerating the nest area, all of which limit their 


\section{G. A. LOZANO \& A. F. H. ROS 20}

foraging opportunities (Santos, 1985a, Ros et al., 2004, Almada et al., 1994, Gonçalves \& Almada, 1997). In contrast, M- males do not incur these costs and hence, their condition does not decrease as it does in M+ males (Gonçalves \& Almada, 1997). Hence, differences in androgens between $\mathrm{M}$ - and $\mathrm{M}+$ males might not directly affect immunity, but rather regulate the allocation of energetic resources between immunity and reproductive behaviour.

Other explanations are not necessarily mutually exclusive. First, nest-holders $(\mathrm{M}+)$ aggressively defend the nest against parasitic males (M-), and while doing so they inflict typical scratch-like injuries with their large canine-like teeth. In Azorean rock-pool blennies, M- males have many more such injuries than nest-holder $\mathrm{M}+$ males. As a consequence $\mathrm{M}$ males are more exposed to potential infections with pathogenic organisms, which might explain why they are more immunocompetent (Ros et al., 2006a). Second, one might expect older males to have been exposed to most of the common pathogens in their environment and to have acquired immunity. As a result older $(\mathrm{M}+)$ males might decrease production of naïve leukocytes which would be necessary for acquiring immunity to new pathogens. Therefore, the fact that if $\mathrm{M}+$ males had lower lymphocyte blood cell counts and lower antibody responsiveness than $\mathrm{M}$ - males does not necessarily mean that they are more susceptible to disease (Ros \& Oliveira, 2009). Under this scenario, the immune system improves with age, but using some measures of immunity, the exact opposite is true. Long term studies in which related individuals are raised in different pathogen and social environments are needed to separate these hypotheses.

The Corkwing wrasse (Symphodus melops) is an intertidal species occurring in the western Mediterranean and Adriatic seas, and in the Eastern Atlantic, from Morocco and the Azores in the South, to Norway in the North. They mostly live in waters less than $5 \mathrm{~m}$ in depth. Adults are 15-25 cm long. Females and juveniles are greenish brown and territorial males are iridescent blue-green. Territorial males build and defend nests where several females might deposit their eggs. In addition, between $2-20 \%$ of males are female mimics, which do not build or defend nests. Female mimics resemble females to the point of having a urogenital papilla similar to that of females. Corkwing wrasses do not change sex, nor do they change male morph. Female mimics of all ages and sizes exit, so it is not a sequential, age or size-dependent polymorphism. It is unknown whether the male morphs are strictly genetically determined, or environmentally determined early in the males' lives. Female mimics are smaller than regular males but have relatively larger gonads, more motile and longer-living sperm than territorial males (Uglem et al., 2000, Potts, 1974, Dipper \& Pullin, 1979, Dipper, 1981, Darwall et al., 1992, Costello, 1991, Quignard \& Pras, 1986). 
Uglem et al. (2001) tested the sperm protection hypothesis and found that territorial males have smaller gonads and larger spleens than female mimics, but the density of lymphocytes and granulocytes did not differ between the two male morphs. So, the cell counts did not support the hypothesis, and the differences in spleen size were the exact opposite of what is predicted by the sperm protection hypothesis (Uglem et al., 2001). The larger gonads of sneaker morphs are as expected based on sperm competition. Subsequent work confirmed that territorial males have larger gonads and more motile sperm than female mimics, but sex steroids affect only sperm quantity, and not sperm quality (Uglem et al., 2002). Hence, contrary to the sperm protection hypothesis and the $\mathrm{ICHH}$, in this system was no detectable relation between sperm quality, immunity, and hormones.

\section{Birds}

Plumage polymorphisms in birds are fairly common (Galeotti et al., 2003), and are maintained by a variety of processes (Lank, 2002). However, ARTS, as defined in this review, that is, relatively long-term and literally "alternative", occur in only seven species (Krüger, 2008). Although much immunoecological work has been conducted with birds, none of it has been done on the other 6 species with ARTS.

The ruff is a lekking shorebird that breeds in marshes and grasslands in northern Eurasia and winters mostly in Africa. Three morphological and behavioural types of males exist: independents, satellites and faeders. Independents and satellites have elaborate plumage and courtship behaviour (Hogan-Warburg, 1966, van Rhijn, 1991), and faeders are female mimics (Jukema \& Piersma, 2006). About 1\% of males are faeders (Verkuil et al., 2008), $15 \%$ satellites, and the rest independents. Including females, ruffs range in mass from $70 \mathrm{~g}$ to $220 \mathrm{~g}$, with extensive overlap. Independents are the largest and females the smallest. Faeders are at the upper end of the female distribution and the lower end of the male distribution. (Bachman \& Widemo, 1999, Lank et al., 2013). Females carrying the faeder gene are the smallest (Lank et al., 2013). The faeder-like morph arose from the ancestral independent about 3.8 mya, and the satellite 0.5 mya (Lamichhaney et al., 2016, Kupper et al., 2016). Females carry the independent/satellite alleles but express the respective phenotypes only when experimentally exposed to testosterone (Lank et al., 1999).

Faeders migrate to the breeding grounds later that most other males, but earlier than most females (Karlionova et al., 2007). During the breeding season, independents establish lek mating courts defend them against each other but try to attract into their courts satellites and females (van Rhijn, 1991, Höglund \& Lundberg, 1989, Hill, 1991). Satellites do not fight 


\section{G. A. LOZANO \& A. F. H. ROS 22}

but are pecked and chased by independents when they fail to be submissive and when they attempt to mount a visiting female, but they are tolerated because co-occupied courts are more likely to attract females (van Rhijn, 1991, Höglund \& Lundberg, 1989, Hill, 1991). Faeders look like and behave like females, spending time among females and visiting leks unchallenged. Nevertheless, faeders readily copulate when females solicit copulations from independents, satellites or perhaps even faeders.

Lozano and Lank (2004) tested the ICHH and the energetic constraints hypothesis in a captive population. Lozano and Lank (2004) examined whether early in the breeding season, immunity was positively correlated size and the degree of development testosterone-induced sexual traits. This work was conducted before the discovery of faeders. Cell-mediated immunity (CMI) was estimated using a delayed hypersensitivity test and humoral immunity using a SRBC agglutination test. However, other than the fact that CMI was weakly correlated with ruff length, neither measure of immunity was related to any other sexually selected traits, size of mass, in either satellites or independents. Lozano and Lank (2004) also tested the energetic trade-off hypothesis, which predicts that satellites should have stronger immune responses than independents. Although humoral immunity did not differ between the two male morphs, independents had higher CMI responses than satellites. If anything, these results support the "risk of injury" hypothesis. In contrast, during the non-breeding season the immune responses of both morphs were stronger, but despite a larger sample size (51 vs. only 21 males in the breeding season), there were no differences in CMI between the morphs (Lozano \& Lank, 2003). Hence, energetic constraints explain the decrease in immune function during the breeding season, and differences in immunity between independents and satellites during the breeding season are best explained by the potential exposure to injuries.

These two alternatives were subsequently tested by Lozano et al. (2013). This study included the recently discovered fader, the female mimicking male morph. Based on their behaviour and life history, the 3 male morphs and females can be placed on an ordinal scale with independents at one end and females at the other. A haemolysis-haemagglutination assay (Matson et al., 2005) on samples taken before and after an injection with liposaccharide was used to measure innate and adaptive humoral immunity, respectively. Furthermore, CMI was once again estimated via a delayed hypersensitivity test. No significant differences were evident between the four groups, but all three measures of immunity decreases along this axis from independents to females. These results support the risk-of-injury hypothesis over the energetic constrains hypothesis. Hence, the immune responses of the 4 ruff genders reflected their life history and behaviour, with faeders located in the immunological continuum 
between females and the other male morphs. So far in this system, support is lacking for hypotheses predicting a direct hormonal regulation of immune responses.

Additionally, in ruffs CMI decreases significantly with age, in males (Lozano \& Lank, 2004), and in both sexes (Lozano \& Lank, 2003). Nebel et al. (2013) partially confirmed these results, although only for females, and with only one of several immune measures. Although the decrease was not related to morph differences, it is consistent with the basic life-history premise that investment on self-maintenance should decrease as residual reproductive success wanes. Finally, again, although morph differences were not detected, Lozano \& Lank (2003) showed that younger birds have weaker immune responses, presumably because of the way a neonate's immune system develops, by learning which antigens are harmful, or because of energetic constraints as a neonate's resources are channelled primarily towards growth.

\section{Reptiles}

A variety of ARTS exist among reptiles. These include $r$ - and $k$ - life histories, manipulation of offspring sex, territoriality vs. non-territoriality, parthenogenesis vs. sexual reproduction, and behavioural, morphological and chemical female mimicry (Calsbeek \& Sinervo, 2008). Unlike fish, reptiles lack the ability to change sex during adulthood, so the range of reproductive tactics and strategies does not include all of the ones present in fish, but they do include all of the ones present among birds. With reptiles, one must be careful to distinguish between merely polymorphic species and species with ARTS, as defined above.

Several studies have compared immune function of different morphs in polymorphic species. For instance, work was been conducted on the brown anole (Anolis sagrei) (Calsbeek et al., 2008), the wall lizard (Podarcis muralis) (Sacchi et al., 2007, Galeotti et al., 2010), and Iberian wall lizard (Podarcis hispanicus) (Ortega et al., 2015). In these studies, the general rationale seems to be that differences in immune responsiveness, presumably reflecting differences in parasite exposure or susceptibility to disease, contribute to the maintenance of the polymorphism. However, the reasons are not explicitly stated, and the predictions are nebulous. Even when significant differences are found, it is unclear why one morph's immune response would be stronger than the other morph's. In contrast, when using species with ARTS, or merely when considering the morphs' ecology, it is possible to articulate specific directional predictions and design more purposeful tests.

The Dalmatian wall lizard (Podarcis melisellensis) is a species with a range limited to the Adriatic countries. Adults have an SVL of at least $5 \mathrm{~cm}$; they lay 3 clutches per year with 3-9 eggs per clutch, and have a clearly evident trade-off between egg size and number 


\section{G. A. LOZANO \& A. F. H. ROS 24}

(Bejakovic et al., 1995). Males have a SVL of about $6 \mathrm{~cm}$, their ventral surface can be orange, yellow, or white, and they do not change between successive breeding seasons. Although their sizes overlap considerably, orange males are generally larger than either white or yellow males (Huyghe et al., 2007). Hence, it is most likely that the morphs are permanent and established early in life.

Huyghe et al. (2009) compared testosterone, corticosterone, morphology, biting strength, and immunity among the three morphs. Immunity was measured using the aforementioned delayed hypersensitivity test, and by measuring the numbers of mites and ticks. The study was loosely and perhaps retroactively framed around the ICHH. In any case, there were not significant differences among morphs in testosterone or either measure of immunity. Hence, these results did not support the ICH hypothesis.

Subsequently, Huyghe et al. (2010) examined seasonal differences in cell-mediated immunity in males, again using PHA test for cell mediate immunity. Fewer orange individuals were infected with haemogregarines at the end of the season, but white males were always more infected. Compared to the start of the breeding season, at the end of the season CMI had increased in white and yellow males, but it had decreased in orange males. Again, and unfortunately, the authors did not state any a-priori expectations, so it is difficult to interpret the results.

The side-blotched lizard (Uta stansburiana), which is a small (50-60 mm SVL, 7-10 g), highly polymorphic lizard common in the south-west of North America (Tinkle, 1967), where it sometimes reaches densities of up to 2,600 per hectare (Svensson et al., 2001). They mature at one year of age, and usually live for only one breeding season. The species is separated into several populations or sub-species, usually with different types of polymorphisms (Upton \& Murphy, 1997).

In the population studied by Sinervo and colleagues, used for all the studies below, morphs are determined by 3 alleles (o, b, and y). Males occur in three morphs: orange, yellow, and blue. In males, the "o" allele is dominant, and the " $b$ " allele is recessive to the "y" allele (oo, ob, and oy are orange, yb and yy are yellow, and bb are blue). Orange males are aggressive and highly territorial, blue males have smaller territories and are not as aggressive and yellow males are sneakers. Male morphs are maintained via frequency dependent section in a "rock, paper, scissors" system (Sinervo \& Lively, 1996), whereby orange males can take over territories of blue males, but are themselves vulnerable to cuckoldry by yellow males (Sinervo \& Lively, 1996). Females occurs in two morphs, orange and yellow. In females, the "o" allele is also dominant (oo, ob, and oy are orange, yb, yy, and bb are yellow) (Sinervo \& 
Zamudio, 2001). Orange females produce large clutches of small eggs and are favoured at low densities, and yellow females produce small clutches of large eggs and are favoured at high densities. Their relative abundances oscillate in 2-year cycles, driven by negative frequency dependent selection.

Using antibody responsiveness towards a tetanus toxoid antigen in females, Svensson et al. (2001) found that population density was negatively related with immune responsiveness of both morphs but more so in orange females. Furthermore, subsequent survival was positively related to the strength of prior antibody responsiveness in yellow females, but negatively related in orange ones (Svensson et al., 2001). Hence, compared to yellow females, orange females, which are adapted to fast reproduction, invest less in immune function, and are less capable of activating their immune system without suffering negative consequences. These trade-offs are as expected based on life history theory, but seldom are they documented within one sex.

Svensson et al. (2009) extended these findings to include males, examining the population genetics behind colour and humoral immunity. They found orange colour has highly heritable (0.46), and antibody responsiveness to diphtheria-tetanus antigens even more so ( 0.61 for sons and 0.82 for females). However, the correlations between orange colour and antibody responsiveness were in opposite directions for males and females, producing a significant intersexual conflict (Svensson et al., 2009). This means that, assuming there is no post-copulatory mate choice, females cannot simply select males based on "good genes", immunologicallly, but rather must choose between immunocompetent sons or immunocompetent daughters. The implications are yet to be examined.

\section{Insects}

As it might be expected for such a speciose and diverse taxon with distinct life stages, a wide variety of ARTS occur among insects (Brockmann, 2001, Brockmann, 2008). Brockmann (2008) divided reproductive behaviour in insects into four sequential events: (1) locating mates (2) obtaining access to mates, usually females, (3) copulating, and (4) guarding the female after copulation. Except for the very act of copulation ARTS occur in all four types of behaviours. Although the literature on ARTS in insects is extensive, and their immune systems relatively simple compared to that of vertebrates, it is peculiar that few researchers have examined the immunoecology of insects with ARTS.

The beetle Onthophagus taurus is a member of the scarabaeid dung beetle group, taxon in which only males have horns. Diet during the larval stage determines whether 


\section{G. A. LOZANO \& A. F. H. ROS 26}

individuals reach a certain size threshold at a given time in their development, at which point two growth trajectories are followed. Males above the size threshold develop unusually large horns and males below the threshold develop only rudimentary horns. This dimorphism is associated with behavioural dimorphisms. Horned males compete directly with each other in their tunnels for access to females, and guard them after copulation. Hornless males are sneakers and dig across tunnels, enter the tunnels beneath the guarding male and, and undetected by the guarding male, mate with females (Emlen, 1994, Emlen, 1997, Moczek \& Emlen, 1999). Both sexes excavate branched tunnels under dung patties, where females lay their eggs and leave some dung for their offspring to eat when they hatch. However, horned males provide more paternal care than hornless males, but only when there are no other males present (Moczek, 1999).

Cotter et al. (2008) examined immunity in male larvae, after the eventual morph had been determined but before the actual development of horns. At that point in their development, their diet has been slightly different, their size differs, but energetic requirements do not differ much yet. Unfortunately, trade-offs are mentioned but no hypothesis is explicitly addressed, so the expectations are unclear. Nevertheless, using phenoloxidase (PO) activity as a measure of innate immunity, they showed that, controlling for condition, larvae of males that will eventually be horned have higher innate immunity than larvae of eventually hornless males. Perhaps these differences are a prophylactic investment on immune function and reflect future differences in pathogen exposure. Female PO activity was between that of the two male morphs, which would be potentially interesting if there were more explicit hypotheses predicting such a pattern. Because horn growth is induced by juvenile hormone (Emlen \& Nijhout, 1999), Cotter et al. (2008) suggest that juvenile hormone also causes the differences in immunity. This juvenile hormone hypothesis does not depend on energetic trade-offs (proximate or ultimate), but it does provide a mechanism regulating immunity in insects, akin to the suggested androgen mechanisms for vertebrates. This idea is yet to be tested.

Odonates present an interesting contrast in that females, not males, are the ones with alternative morphs. In many species, more so among damsleflies (zygoptera), there can be one or more female morphs (called gynomorphs or gynochromes), and a male mimicking morph (andromorphs or androchromes). Andromorphs mimic both male morphology and behaviour. Compared to gynomorphs, andromorphs are brightly coloured and have narrower abdomens, and they are more aggressive and more likely to roam about in open spaces (Robertson, 1985). The polymorphism is based on a female-restricted autosomal system with 2 or 3 alleles 
(Johnson, 1966, Johnson, 1964, Andrés \& Cordero, 1999). The proportion of andromorphs is highly variable, but generally, polymorphisms are more common in populations with relatively more males (Iserbyt et al., 2009, van Gussum et al., 2007). For example, in Ischnura elegans, depending on the population, andromorphs constitute $14 \%$ to $94 \%$ of all females (Sanchez-Guillon et al., 2013). In Nehalennia irene (Hagen) across Canada, andromorph frequencies range from 0 to $>90 \%$ (van Gussum et al., 2007).

Andromorphs are subjected to less sexual harassment than gynomorphs. For instance, Ischnura senegalensis males harass gynomorphs more than they do andromorphs; compared to andromorphs, gynomorphs do not defecate as much, which presumably reflects their food intake, and most importantly, they produce 35\% fewer eggs (Takahashi \& Watanabe, 2010). In Ischnura elegans, andromorphs mate less often than gynomorphs, and males are more attracted to gynomorphs (Cordero et al., 1998). As usual, the picture is not so simple. Another study of Ischnura elegans showed that naïve males prefer andromorph over gynomorph females, but experienced males have no such preference (Sanchez-Guillon et al., 2013).

Although the consensus is that alternative female morphs are maintained, and perhaps evolved, because they help females decrease male harassment, that argument just reverses the question. Without a cost to being and andromorph, andromorphs would reach fixation. Sanchez-Guillen et al. (2013) suggested that andromorphs are more conspicuous and more exposed to parasites than gynomorphs, so increased parasitism might counterbalance the benefits of reduced male harassment: the "exposure risk" hypothesis. They tested the idea by quantifying the prevalence of intestinal gregarines (Apicomplexa: Eugregarinidae) and aquatic water mites (Arrenurus sp.) in several species of damselflies. Gregarine prevalence did not differ between the morphs, but, as predicted, mite prevalence was higher in andromorphs than in gynomorphs.

Joop et al. (2006) conducted a similar study using the azure damselfly (Coenagrion puella). Once again, the general rationale is that differences in immune responsiveness contribute to the maintenance of the polymorphism, but the reasons are not explicitly stated. A link to melanin is mentioned, curiously, more prominently in the abstract than in the body of the paper, but the link is not explained. The andromorph is blue, the gynomorph is green, and as one might expect, the intermediate is blue-green. These colours are more likely to be structural, not melanin dependent, and nothing in the paper indicates otherwise. Nevertheless, no differences were found among the morphs in the prevalence of water mites or gregarines. Furthermore, following an experimental fungal infection, there were no differences in resistance among female morphs. 


\section{G. A. LOZANO \& A. F. H. ROS 28}

\section{Discussion and Conclusions}

In several immunological studies in species with ARTS, the hypotheses and predictions are not clearly articulated. Males and females are dissimilar in so many ways that it is not surprising to find one more difference (e.g., Konerding et al., 2016). Differences between the 2 sexes could be predicted using relatively weak arguments, but if differences are found, there is no way of really knowing whether they indeed support a particular hypothesis. However, when species with ARTS are compared, even the weakest logic would yield falsifiable, $a$ priori, directional predictions, so spurious supporting results would be less likely. This problem is particularly puzzling because the main benefit of using species with ARTS is that hypotheses predicting differences between two sexes could actually be more thoroughly tested by taking advantage of the additional morph(s). Furthermore, most studies tend to test only one hypothesis, which is particularly troubling in cases in which related alternative hypotheses, preferably with contrasting predictions, could be incorporated into the study.

The paucity of work on insects is surprising. Let us be clear. There is plenty of work on insect polymorphisms, and some of it on immunity; however, we were not able to find many immunoecological studies in species with alternative life histories. There are myriad benefits to working with insects. Generally, the sheer number of species of insects, and arthropods in general, means that researchers could find the best possible species with which to test a particular hypothesis. Second, given their small size, obtaining a reasonable sample size becomes less of a problem. Also, it goes without saying that it is easier to get permits to work with insects. There are also other benefits to working with insects more specifically relevant to immunoecology in species with ARTS. First, many types of polymorphisms, both morphological and/or behavioural, have already been described in insects (Brockmann, 2008), and many of these are technically "alternative". Second, compared to vertebrates, their immune systems are relatively simple, so it might be easier to focus on the ecology and avoid being bogged down by the mechanisms of immunity. For instance, their immune system does not have immunological memory (Söderhäll, 2010); therefore, should experimental design require it, repeatedly assessing the immune systems of individuals would not compromise the study's validity. Hence, researchers who are truly interested in trade-offs between maintenance and reproduction in species with alternative life histories, and who are not required to work on vertebrates, would do well by choosing to work with insects.

For nearly 25 years now, the ICHH, has been a starting point for many studies, but maybe it has had too much influence. Instead of being fully integrated with the ICHH, 
ecological and resource constraint studies seem to have been relatively ignored. Furthermore, the ICHH has not been supported, and even if it is still considered a convenient starting point, it is time to consider the alternatives and examine the subtleties. For instance, by examining several indices of immunity and several androgen hormones, studies can increase the chances of finding some support for the hypotheses. However, different androgens often have different effects on different aspects of the immune system, but there are never any evolutionary, ecological, or phylogenetic explanations of why some androgens, but not others, should affect immunity in that particular way. It is at this point that the unification of the ecological and the physiological approaches begins to disintegrate and the focus is shifted to physiological mechanisms. In immunoecology, as in any branch of physioecology, we must remain keenly aware that the proximate and ultimate approaches pull us in different directions. It seems that evolutionary ecologists are easily seduced by the sophisticated instrumentation and technical complexity of the reductionist approach, in the process forgetting the evolutionary history and ecological intricacies of their beloved organisms.

In evolutionary ecology, hypotheses must not merely deal with physiology and mechanisms but also address the far more relevant question of how ecological and evolutionary forces have produced these particular mechanisms. One possible fruitful way to merge the two approaches might be to start with how ecology and life-history not only affect immunity, but more specifically, when and how they would activate and/or suppress immune function. Many papers focus on immunosuppression or immunotolerance and give adaptive explanations for this in terms of trade-offs or in terms of energetic constraints. However, all these could be divided into two general situations that might determine when to: 1) activate or stimulate immunity, for instance, to fight a new pathogen, and 2) suppress or subdue it, for instance, to temporarily tolerate a parasite. A suitable regulation mechanism is one that is flexible enough so it can respond to ecological opportunities, both during an individual's lifetime and at evolutionary time scales (Hau, 2007). For example, we could show that environmental challenges typical for the ecology of $P$. parvicornis are related with immune activation. More wounds in M- was positively related with higher immunocompetence. As Mmales have more future reproductive potential than the older nesting males, young should primarily invest in survival and gradually (as M-) shift that investment to reproduction. Thus the trade-off between immunocompetence and reproduction will change with age and with the particular morph. Similar conceptual frameworks merging the ultimate and proximate approaches might be necessary for continued development of immunoecology, and in particular when dealing with species with ARTS. 


\section{G. A. LOZANO \& A. F. H. ROS 30}

Interactions between hosts and parasites are yet to be fully examined in the evolution of ARTS. Parasites, and hence immunity, might also play a role in the evolution of ARTS (Todd, 2007). Alternative morphs may arise because of differential parasite resistance strategies, especially when parasite resistance is modulated by a hormone that is also involved in reproductive investment (Zera \& Harshman, 2001). Empirical work, on which the ICHH and its derivatives are based, documents the existence of such trade-offs. Given this trade-off, dominant males may be more susceptible to the parasites, which would lower their ability to defend their reproductive resources and sexual partners. Furthermore, by definition, parasites have the potential to decrease their hosts' fitness, but many parasites co-evolve with their hosts and reduce their virulence but increase their reproduction. Consequently, older hosts might be more infected and more chronically infected than younger hosts. The burden of parasitism might lower the condition of dominant males and facilitate the evolution of ARTS.

Finally, several recent studies have specifically addressed genomics in species with ARTS (Pointer et al., 2013, Schunter et al., 2014, Stuglik et al., 2014). Species with ARTS are, obviously, great systems in which to examine sex or morph-specific gene expression. Using these rapidly advancing techniques, it is now possible to identify large number of genes involved in the development of morphs and the regulation of immunity, and conduct truly integrative studies across all levels of complexity. However, no technical advance is without its conceptual detractors. Because of polygenic effects on phenotypes, the reciprocating modifying effects of organisms and their environments, and the fact that several evolutionary and ecological selection regimes can produce a given genome, it has been argued that further genomic details will distract us from our goals and detract from our understanding (Travisano \& Shaw, 2013). Others acknowledge the pitfalls, but advocate cautious optimism (Zuk \& Balenger, 2014). In the case of ARTS, knowing the genetic basis of morph development and immune regulation within each morph might provide unexpected insights, but without ecological and evolutionary hypotheses driving the effort, we will not really know how immunity interacts with the evolution and maintenance of these morphs. Decoding entire genomes and disentangling physiological mechanisms can be informative, but there is no grandeur in the strict reductionist view of life.

\section{Acknowledgements}

G.A.L. thanks the University of Tartu library for allowing him free access to their online collections and L. Prigo for getting books from the said library under her name. This is paper 
contribution number 1614 of the ECEE. We appreciated the comments Corinna von Kürthy made on a previous version.

\section{References}

Alcock, J. (1979) The evolution of intraspecific diversity in male reproductive patterns in some bees and wasps. In: Sexual Selection and Reproductive Competition in Insects, (Blum, M. S. \& Blum, N. A., eds.). pp. 381-402. Academic Press, New York.

Allander, K. \& Bennett, G. F. 1995. Retardation of breeding onset in great tits (Parus major) by blood parasites. Functional Ecology 9: 677-682.

Almada, V. \& Robalo, J. I. (2008) Phylogenetic analysis of alternative reproductive tactics: problems and possibilities. In: Alternative reproductive tactics: an integrative approach, (Oliveira, R. F., Taborsky, M. K. \& Brockmann, H. J., eds.). pp. 52-62. Cambridge University Press, Cambridge.

Almada, V. C., Gonçalves, E. J., Santos, A. J. \& Baptista, C. 1994. Breeding ecology and nest aggregations in a population of Salaria pavo (Pisces: Blenniidae) in an area where nest sites are very scarce. Journal of Fish Biology 45: 819-830.

Andersson, M. 1994. Sexual Selection. Princeton University Press, Princeton, NJ.

Andrés, J. A. \& Cordero, A. 1999. The inheritance of female colour morphs in the damselfly Ceriagrion tenellum (Odonata, Coenagrionidae). Heredity 82: 328-335.

Ardia, D. R. 2005. Tree swallows trade off immune function and reproductive effort differently across their range. Ecology 86: 2040-2046.

Ardia, D. R., Schat, K. A. \& Winkler, D. W. 2003. Reproductive effort reduces long-term immune function in breeding tree swallows (Tachycineta bicolor ). Proceedings of the Royal Society of London B 270: 1679-1683.

Bachman, L. \& Widemo, F. 1999. Relationships between body composition, body size and alternative reproductive tactics in a lekking sandpiper, the ruff (Philomachus pugnax). Functional Ecology 13: 411-416.

Barr, D. P., Russell, M. D., Cecil, L. \& Du Boise, E. F. 1922. Clinical calorimetry XXXII: temperature regulation after the intravenous injections of protease and typhoid vaccine Archives of Internal Medicine 29: 608-634.

Barron, D. G., Webster, M. S. \& Schwabl, H. 2015. Do androgens link morphology and behaviour to produce phenotype-specific behavioural strategies? Animal Behaviour 100: $116-124$.

Bateman, A. J. 1948. Intra-sexual selection in Drosophila. Heredity 2: 349-368.

Bejakovic, D., Kalezic, M. L., Aleksic, I., Dzukic, G. \& Crnobrnja-Isailovic, J. 1995. Female reproductive cycle and clutch traits in the Dalmatian wall lizard (Podarcis melisellensis). Folia Zoologica 44: 371-380.

Bielak, A. P., Skrzynecka, A. M., Miler, K. \& Radwan, J. 2014. Selection for alternative male reproductive tactics alters intralocus sexual conflict. Evolution 68: 2137-2144.

Boonekamp, J. J., Ros, A. F. H. \& Verhulst, S. 2008. Immune activation suppresses plasma testosterone level: a meta-analysis. Biology Letters 4: 741-744.

Braude, S., Tang-Martinez, Z. \& Taylor, G. T. 1999. Stress, testosterone, and the immunoredistribution hypothesis. Behavioral Ecology 10: 345-350.

Brockmann, H. J. (2001) The evolution of alternative strategies and tactics Vol. 30 (Slater, P. J. B., Rosenblatt, J. S., Snowdon, C. T. \& Roper, T. J., eds.). pp. 1-51 Advances in the Study of Behavior. Academic Press, New York. 


\section{G. A. LOZANO \& A. F. H. ROS 32}

Brockmann, H. J. (2008) Alternative reproductive tactics in insects. In: Alternative reproductive tactics: an integrative approach, (Oliveira, R. F., Taborsky, M. K. \& Brockmann, H. J., eds.). pp. 177-223. Cambridge University Press, Cambridge.

Calsbeek, R., Bonneaud, C. \& Smith, T. B. 2008. Differential fitness effects of immunocompetence and neighbourhood density in alternative female lizard morphs. Journal of Animal Ecology 77: 103-109.

Calsbeek, R. \& Sinervo, B. (2008) Alternative reproductive tactics in reptiles. In: Alternative Reproductive Tactics, (Oliveira, R. F., Taborsky, M. \& Brockmann, H. J., eds.). pp. 332-342. Cambridge University Press, Cambridge.

Caro, T. M. \& Bateson, P. 1986. Organization and ontogeny of alternative tactics. Animal Behaviour 34: 1483-1499.

Charnov, E. L. 1982. The Theory of Sex Allocation. Princeton University Press, Princeton, NJ.

Cordero, A., Carbone, S. S. \& Utzeri, C. 1998. Mating opportunities and mating costs are reduced in androchrome female damselflies, Ischnura elegans (Odonata). Animal Behaviour 55: 185-197.

Corl, A., Davis, A. R., Kuchta, S. R. \& Sinervo, B. 2010. Selective loss of polymorphic mating types is associated with rapid phenotypic evolution during morphic speciation. Proceedings of the National Academy of Sciences, U.S.A. 107: 4254-4259.

Costello, M. J. 1991. Review of the biology of wrasse (Labridae: Pisces) in northern Europe. Progress in Underwater Science 16: 29-51.

Cotter, S. C., Beveridge, M. \& Simmons, L. W. 2008. Male morph predicts investment in larval immune function in the dung beetle, Onthophagus taurus. Behavioral Ecology 19: 331-337.

Crespi, B. J. 1986. Size assessment and alternative fighting tactics in Elaphrothrips tuberculatus (Insecta: Thysanoptera). Animal Behaviour 34: 1324-1335.

Cummings, M. E. \& Ramsey, M. E. 2015. Mate choice as social cognition: predicting female behavioral and neural plasticity as a function of alternative male reproductive tactics. Current Opinion in Behavioral Sciences 6: 125-131.

Dabbert, C. B., Lochmiller, R. L. \& Teeter, R. G. 1997. Effects of acute thermal stress on the immune system on the northern bobwhite (Colinus virginianus). Auk 114: 103-109.

Danforth, B. N. 1991. The morphology and behavior of dimorphic males in Perdita portalis (Hymenoptera: Andrenidae). Behavioral Ecology and Sociobiology 29: 235-247.

Danforth, B. N. \& Neff, J. L. 1992. Male polymorphism and polyethism in Perdita texana (Hymenoptera: Andrenidae). Annals of the Entomological Society of America 85: 616626.

Darwall, W. R. T., Costello, M. J., Donnelly, R. \& Lysaght, S. 1992. Implications of lifehistory strategies for a new wrasse fishery. Journal of Fish Biology 41: 111-123.

Darwin, C. 1871. The descent of man and selection in relation to sex, $1 \mathrm{st}$ ed. John Murray, London.

Demas, G. E., Chefer, V., Talan, M. I. \& Nelson, R. J. 1997. Metabolic costs of mounting an antigen-stimulated immune response in adult and aged C57BL/6J mice. American Journal of Physiology - Regulatory Integrative and Comparative Physiology 273: R1631-R1637.

Dingle, H. \& Winchell, R. 1997. Juvenile hormone as a mediator of plasticity in insect life histories. Archives of Insect Biochemistry and Physiology 35: 359-373.

Dipper, F. A. 1981. The strange sex lives of British wrasse. New Scientist 90: 444-445.

Dipper, F. A. \& Pullin, R. S. V. 1979. Gonochorism and sex-inversion in British Labridae (Pisces). Journal of Zoology 187: 97-112.

Ehlinger, T. J. \& Wilson, D. S. 1988. Complex foraging polymorphims in bluegill sunfish. Proceedings of the National Academy of Sciences, U.S.A. 85: 1989-1882. 
Emlen, D. J. 1994. Environmental control of horn length dimorphism in the beetle Onthophagus acuminatus Coleoptera, Scarabaeidae. Proceedings of the Royal Society of London B 265: 131-136.

Emlen, D. J. 1997. Alternative reproductive tactics and male-dimorphism in the horned beetle Onthophagus acuminatus (Coleoptera: Scarabaeidae). Behavioral Ecology and Sociobiology 41: 335-341.

Emlen, D. J. (2008) The roles of genes and the environment in the expression and evolution of alternative tactics. In: Alternative reproductive tactics: an integrative approach, (Oliveira, R. F., Taborsky, M. K. \& Brockmann, H. J., eds.). pp. 85-108. Cambridge University Press, Cambridge.

Emlen, D. J. \& Nijhout, H. F. 1999. Hormonal control of male horn length dimorphism in the dung beetle Onthophagus taurus (Coleoptera: Scarabaeidae). Journal of Insect Physiology 45: 45-53.

Fisher, R. 1930. The Genetical Theory of Natural Selection. The Clarendon Press.

Fleming, I. A. 1996. Reproductive strategies of Atlantic salmon: ecology and evolution. Reviews in Fish Biology and Fisheries 6: 379-416.

Fleurance, G., Duncan, P., Fritz, H., Cabaret, J., Cortet, J. \& Gordon, I. J. 2007. Selection of feeding sites by horses at pasture: testing the anti-parasite theory. Applied Animal Behaviour Science 108: 288-301.

Folstad, I. \& Karter, A. J. 1992. Parasites, bright males, and the immunocompetence handicap. American Naturalist 139: 603-622.

Galeotti, P., Pellitteri-Rosa, D., Sacchi, R., Gentilli, A., Pupin, F., Rubolini, D. \& Fasola, M. 2010. Sex-, morph- and size-specific susceptibility to stress measured by haematological variables in captive common wall lizard Podarcis muralis. Comparative Biochemistry and Physiology, Part A 157: 354-363.

Galeotti, P., Rubolini, D., Dunn, P. O. \& Fasola, M. 2003. Colour polymorphism in birds: causes and functions. Journal of Evolutionary Biology 16: 635-646.

Garant, D., Dodson, J. J. \& Bernatchez, L. 2003. Differential reproductive success and heritability of alternative reproductive tactics in wild Atlantic salmon (Salmo salar L.). Evolution 57: 1133-1141.

Gonçalves, D., Matos, R., Fagundes, T. \& Oliveira, R. 2005. Bourgeois males of the peacock blenny, Salaria pavo, discriminate female mimics from females? Ethology 111: 559572.

Gonçalves, E. J. \& Almada, V. C. 1997. Sex differences in resource utilization by the peacock blenny. Journal of Fish Biology 51: 624-633.

Gross, M. R. 1991. Evolution of alternative reproductive strategies: frequency- dependent sexual selection in male bluegill sunfish. Philosophical Transactions of the Royal Society of London B 332: 59-66.

Grutter, A. 1996. Parasite removal rates by the cleaner wrasse Labroides dimidiatus. Marine Ecology Progress Series 130: 61-70.

Haddad, C. F. B. \& Prado, C. P. A. 2005. Reproductive modes in frogs and their unexpected diversity in the Atlantic forest of Brazil. BioScience 55: 207-217.

Hart, B. L. 1990. Behavioural adaptations to pathogens and parasites: five strategies. Neuroscience and Biobehavioral Reviews 14: 273-294.

Hasselquist, D. \& Nilsson, J. A. 2009. Maternal transfer of antibodies in vertebrates: transgenerational effects on offspring immunity. Philosophical Transactions of the Royal Society B 364: 51-60.

Hau, M. 2007. Regulation of male traits by testosterone: implications for the evolution of vertebrate life histories. BioEssays 29: 133-144. 


\section{G. A. LOZANO \& A. F. H. ROS 34}

Hill, W. L. 1991. Correlates of male mating success in the ruff Philomachus pugnax, a lekking shorebird. Behavioral Ecology and Sociobiology 29: 367-372.

Hillgarth, N., Ramenofsky, M. \& Wingfield, J. 1997. Testosterone and sexual selection. Behavioral Ecology 8: 108-112.

Hogan-Warburg, A. L. 1966. Social behaviour of the ruff, Philomachus pugnax (L.). Ardea 54: 109-229.

Höglund, J. \& Lundberg, A. 1989. Plumage color correlates with body size in the Ruff (Philomachus pugnax). Auk 106: 336-338.

Holland, B. \& Rice, W. R. 1998. Chase-away sexual selection: antagonistic seduction versus resistance. Evolution 52: 1-7.

Houston, T. F. 1970. Discovery of an apparent soldier caste in a nest of a halictine bee (Hymenoptera: Halictidae), with notes on the nest. Australian Journal of Zoology 18: 345-351.

Huyghe, K., Husak, J. F., Herrel, A., Tadić, Z., Moore, I. T., van Damme, R. \& Vanhooydonck, B. 2009. Relationships between hormones, physiological performance and immunocompetence in a color-polymorphic lizard species, Podarcis melisellensis. Hormones and Behavior 55: 488-494.

Huyghe, K., van Oystaeyen, A., Pasmans, F., Tadić, Z., Vanhooydonck, B. \& van Damme, R. 2010. Seasonal changes in parasite load and a cellular immune response in a colour polymorphic lizard. Oecologia 163: 867-874.

Huyghe, K., Vanhooydonck, B., Herrev, A., Tadic, Z. \& van Dammet, R. 2007. Morphology, performance, behavior and ecology of three color morphs in males of the lizard Podarcis melisellensis. Integrative and Comparative Biology 47: 211-220.

Iserbyt, A., Bots, J., Ting, J. J., Pérez Jvostov, F., Forbes, M. R., Sherratt, T. N. \& van Gossum, H. 2009. Multi-annual variation in female morph frequencies of the polymorphic damselfly, Nehalennia irene, at continental and regional scales. Animal Biology 59: 313-326.

Johnson, C. 1964. The inheritance of female dimorphism in the damselfly, Ischnura damula. Genetics 49: 513-519.

Johnson, C. 1966. Genetics of female dimorphism in Ischnura demorsa. Heredity 21: 453-459.

Joop, G., Mitschke, A., Rolff, J. \& Siva-Jothy, M. T. 2006. Immune function and parasite resistance in male and polymorphic female Coenagrion puella. BMC Evolutionary Biology 6.

Joop, G. \& Rolff, J. 2004. Plasticity of immune function and condition under the risk of predation and parasitism. Evolutionary Ecology Research 6: 1051-1062.

Jukema, J. \& Piersma, T. 2006. Permanent female mimics on a lekking shorebird. Biology Letters 2: 161-164.

Karlionova, N., Pinchuk, P., Meissner, W. \& Verkuil, Y. 2007. Biometrics of ruffs Philomachus pugnax migrating in spring through southern Belarus with special emphasis on the occurrence of 'faeders'. Ringing and Migration 23: 134-140.

Ketterson, E. D. \& Nolan, V. 1999. Adaptation, exaptation, and constraint: a hormonal perspective. American Naturalist 154: S4-S25.

Keymer, A., Crompton, D. W. T. \& Sahakian, B. J. 1983. Parasite-induced learned taste aversion involving Nippostrongylus in rats. Parasitology 86: 455-460.

Kokko, H. \& Rankin, D. J. 2006. Lonely hearts or sex in the city? density-dependent effects in mating systems. Philosophical Transactions of the Royal Society B 361: 319-334.

Konerding, W. S., Zimmermann, E., Bleich, E., Hedrich, H.-J. \& Scheumann, M. 2016. Female cats, but not males, adjust responsiveness to arousal in the voice of kittens. BMC Evolutionary Biology 16: 1-9. 
Krüger, O. (2008) Alternative reproductive tactics in birds. In: Alternative Reproductive Tactics, (Oliveira, R. F., Taborsky, M. \& Brockmann, H. J., eds.). pp. 353-355. Cambridge University Press, Cambridge.

Kukuk, P. F. \& Schwarz, M. P. 1988. Macrocephalic male bees as functional reproductives and probable guards. Pan-Pacific Entomologist 64, : 131-137.

Kupper, C., Stocks, M., Risse, J. E., dos Remedios, N., Farrell, L. L., McRae, S. B., Morgan, T. C., Karlionova, N., Pinchuk, P., Verkuil, Y. I., Kitaysky, A. S., Wingfield, J. C., Piersma, T., Zeng, K., Slate, J., Blaxter, M., Lank, D. B. \& Burke, T. 2016. A supergene determines highly divergent male reproductive morphs in the ruff. Nature Genetics 48: 79-83.

Lamichhaney, S., Fan, G., Widemo, F., Gunnarsson, U., Thalmann, D. S., Hoeppner, M. P., Kerje, S., Gustafson, U., Shi, C., Zhang, H., Chen, W., Liang, X., Huang, L., Wang, J., Liang, E., Wu, Q., Lee, S. M. Y., Xu, X., Hoglund, J., Liu, X. \& Andersson, L. 2016. Structural genomic changes underlie alternative reproductive strategies in the ruff (Philomachus pugnax). Nature Genetics 48: 84-88.

Lande, R. 1980. Sexual dimorphism, sexual selection, and adaptation in polygenic characters. Evolution 34: 292-305.

Lank, D. B. 2002. Diverse processes maintain plumage polymorphisms in birds. Journal of Avian Biology 33: 327-330.

Lank, D. B., Coupe, M. \& Wynne-Edwards, K. E. 1999. Testosterone-induced male traits in female ruffs (Philomachus pugnax): autosomal inheritance and gender differentiation. Proceedings of the Royal Society of London, Series B 266: 2323-2330.

Lank, D. B., Farrell, L. L., Burke, T., Piersma, T. \& McRae, S. B. 2013. A dominant allele controls development into female mimic male and diminutive female ruffs. Biology Letters 9.

Lawson, H. A., Cady, J. E., Partridge, C., Wolf, J. B., Semenkovich, C. F. \& Cheverud, J. M. 2011. Genetic effects at pleiotropic loci are context-dependent with consequences for the maintenance of genetic variation in populations. PLoS Genetics 7: e1002256.

Liljedal, S. \& Folstad, I. 2003. Milt quality, parasites, and immune function in dominant and subordinate Arctic charr. Canadian Journal of Zoology 81: 221-227.

Lindström, K. M., Foufopoulos, J., Pärn, H. \& Wikelski, M. 2004. Immunological investments reflect parasite abundance in island populations of Darwin's finches. Proceedings of the Royal Society B 271: 1513-1519.

López, P., Moreira, P. L. \& Martín, J. 2009. Chemical polymorphism and chemosensory recognition between Iberolacerta monticola lizard color morphs. Chemical Senses 34: 723-731.

Lozano, G. A. (1998) Parasitic stress and self-medication in wild animals. In: Stress and Behavior, Vol. 27 (Møller, A. P., Milinski, M. \& Slater, P. J. B., eds.). pp. 291-317 Advances in the Study of Behavior. Academic Press, San Diego, CA.

Lozano, G. A. \& Lank, D. 2004. Immunocompetence and testosterone-induced condition traits in male ruffs (Philomachus pugnax). Animal Biology 54: 315-329.

Lozano, G. A. \& Lank, D. B. 2003. Seasonal trade-offs in cell-mediated immunosenescence in ruffs (Philomachus pugnax). Proceedings of the Royal Society of London B 270: 1203-1208.

Lozano, G. A., Lank, D. B. \& Addison, B. 2013. Immune and oxidative stress trade-offs in four classes of ruffs (Philomachus pugnax) with different alternative reproductive strategies. Canadian Journal of Zoology 91: 212-218.

Lozano, G. A. \& Ydenberg, R. C. 2002. Transgenerational effects of maternal immune challenge in tree swallows (Tachycineta bicolor). Canadian Journal of Zoology 80: 918-925. 


\section{G. A. LOZANO \& A. F. H. ROS 36}

Marais, M., Maloney, S. K. \& Gray, D. A. 2011. The metabolic cost of fever in Pekin ducks. Journal of Thermal Biology 36: 116-120.

Måsvær, M., Liljedal, S. \& Folstad, I. 2004. Are secondary sex traits, parasites and immunity related to variation in primary sex traits in the Arctic charr? Proceedings of the Royal Society of London B (Supplement) 271: S40-S42.

Matson, K. D., Ricklefs, R. E. \& Klasing, K. C. 2005. A hemolysis-hemagglutination assay for characterizing constitutive innate humoral immunity in wild and domestic birds. Developmental and Comparative Immunology 29: 275-286.

Maynard-Smith, J. 1982. Evolution and the Theory of Games. Cambridge University Press, Cambridge.

Mayor, A. 2009. The Poison King: the Life and Legend of Mithradates, Rome's Deadliest Enemy. Princeton Universty Press.

Moczek, A. P. 1999. Facultative paternal investment in the polyphenic beetle Onthophagus taurus: the role of male morphology and social context. Behavioral Ecology 10: 641647.

Moczek, A. P. \& Emlen, D. J. 1999. Proximate determination of male horn dimorphism in the beetle Onthophagus taurus (Coleoptera: Scarabaeidae). Journal of Evolutionary Biology 12: 27-37.

Moore, M. C. 1991. Application of organization-activation theory to alternative male reproductive strategies: a review. Hormones and Behavior 25: 154-179.

Moore, M. C., Hews, D. K. \& Knapp, R. 1998. Hormonal control and evolution of alternative male phenotypes: generalizations of models for sexual differentiation. American Zoologist 38: 133-151.

Morris, M. R., Goedert, D., Abbott, J. K., Robinson, D. M. \& Rios-Cardenas, O. (2013) Intralocus tactical conflict and the evolution of alternative reproductive tactics. In: Advances in the Study of Behavior, Vol. 45 (Brockmann, H. J., Roper, T. J., Naguib, M., Mitani, J. C., Simmons, L. W. \& Barrett, L., eds.). pp. 447-478.

Muehlenbein, M. P., Hirschtick, J. L., Bonner, J. Z. \& Swartz, A. M. 2010. Toward quantifying the usage costs of human immunity: altered metabolic rates and hormone levels during acute immune activation in men. American Journal of Human Biology 22: 546-556.

Murray, M. D. 1987. Effects of host grooming on louse populations. Parasitology Today 3: 276-278.

Nebel, S., Buehler, D. A., Kubli, S., Lank, D. B. \& Guglielmo, C. G. 2013. Does innate immune function decline with age in captive ruffs Philomachus pugnax? Animal Biology 63: 233-240.

Nelson, R. J. 2004. Seasonal immune function and sickness responses. Trends in Immunology 25: $187-192$.

Noble, D. W. A., Wechmann, K., Keogh, J. S. \& Whiting, M. J. 2013. Behavioral and morphological traits interact to promote the evolution of alternative reproductive tactics in a lizard. American Naturalist 182: 726-742.

Nunn, C. L., Lindenfors, P., Pursall, E. R. \& Rolff, J. 2009. On sexual dimorphism in immune function. Philosophical Transactions of the Royal Society B 364: 61-69.

O'Donnell, S. 1996. Reproductive potential and division of labor in wasps: are queen and worker behavior alternative strategies? Ethology, Ecology \& Evolution 8: 305-308.

O'Neal, D. M. 2013. Eco-endo-immunology across avian life history stages. General and Comparative Endocrinology 190: 105-111.

Oliveira, R. F., Canário, A. V. M., Grober, M. S. \& Santos, R. S. 2001. Endocrine correlates of male polymorphism and alternative reproductive tactics in the Azorean rockpool 
blenny, Parablennius sanguinolentus parvicornis General and Comparative Endocrinology 121: 278-288.

Oliveira, R. F., Canário, A. V. M. \& Ros, A. F. H. (2008a) Hormones and alternative reproductive tactics in vertebrates. In: Alternative Reproductive Tactics, (Oliveira, R. F., Taborsky, M. \& Brockmann, H. J., eds.). pp. 132-173. Cambridge University Press, Cambridge.

Oliveira, R. F., Ros, A. F. H. \& Gonçalves, D. M. 2005. Intra-sexual variation in male reproduction in teleost fish: a comparative approach. Hormones and Behavior 48: 430439.

Oliveira, R. F., Taborsky, M. \& Brockmann, H. J. 2008b. Alternative Reproductive Tactics. Cambridge University Press, Cambridge.

Ortega, J., Pellitteri-Rosa, D., López, P. \& Martín, J. 2015. Dorsal pattern polymorphism in female Iberian wall lizards: differences in morphology, dorsal coloration, immune response, and reproductive investment. Biological Journal of the Linnean Society 116: 352-363.

Phoenix, C. H., Goy, R. W., Gerall, A. A. \& Young, W. C. 1959. Organizing action of prenatally administered testosterone proprionate on the tissues mediating behavior in the female guinea pig. Endocrinology 65: 369-382.

Pianka, E. R. \& Parker, W. S. 1975. Age-specific reproductive tactics. American Naturalist 109: 453-464.

Piersma, T. 1997. Do global patterns of habitat use and migration strategies co-evolve with relative investment in immunocompetence due to spatial variation in parasite pressure? Oikos 80: 623-631.

Pizzolon, M., Giacomello, E., Marri, L., Marchini, D., Pascoli, F., Mazzoldi, C. \& Rasotto, M. B. 2010. When fathers make the difference: efficacy of male sexually selected antimicrobial glands in enhancing fish hatching success. Functional Ecology 24: 141148.

Pointer, M. A., Harrison, P. W., Wright, A. E. \& Mank, J. E. 2013. Masculinization of gene expression is associated with exaggeration of male sexual dimorphism. PLoS Genetics 9.

Potts, G. W. 1974. The coloration and its behavioural significance in the corkwing wrasse Crenilabrus melops. Journal of the Marine Biology Association of the UK 54: 925-938.

Quignard, J.-P. \& Pras, A. (1986) Labridae. In: Fishes of the north-eastern Atlantic and the Mediterranean, Vol. 2 (Whitehead, P. J. P., Bauchot, M. L., Hureau, J.-C., Nielson, J. \& Tortonese, E., eds.). pp. UNESCO, Paris.

Ramnath, K.-M. N. 2009. Behavioral effects of parasitism in animals. Journal of Exotic Pet Medicine 18: 254-265.

Rhen, T. \& Crews, D. 2002. Variation in reproductive behaviour within a sex: neural systems and endocrine activation. Journal of Neuroendocrinology 14: 517-531.

Roberts, M. L., Buchanan, K. L. \& Evans, M. R. 2004. Testing the immunocompetence handicap hypothesis: a review of evidence. Animal Behaviour 68: 227-239.

Robertson, H. M. 1985. Female dimorphism and mating behaviour in a damselfly, Ischnura ramburi: females mimicking males. Animal Behaviour 33: 805-809.

Roff, D. A. 2002. Life History Evolution. Sinauer Associates.

Roff, D. A. \& Fairbairn, D. J. 1991. Wing dimorphisms and the evolution of migratory polymorphisms among the Insecta. American Zoologist 31: 243-251.

Rolff, J. 2002. Bateman's principle and immunity. Proceedings of the Royal Society of London B 269: 867-872. 


\section{G. A. LOZANO \& A. F. H. ROS 38}

Romeo, R. D. 2003. Puberty: a period of both organizational and activational effects of steroid hormones on neurobehavioural development. Journal of Neuroendocrinology 15: $1185-1192$.

Ros, A. F. H., Bouton, N., Santos, R. S. \& Oliveira, R. F. 2006a. Alternative male reproductive tactics and the immunocompetence handicap in the Azorean rock-pool blenny, Parablennius parvicornis. Proceedings of the Royal Society B 273: 901-909.

Ros, A. F. H., Bruintjes, R., Santos, R. S., Canario, A. V. M. \& Oliveira, R. F. 2004. The role of androgens in the trade-off between territorial and parental behavior in the Azorean rock-pool blenny, Parablennius parvicornis. Hormones and Behavior 46: 491-497.

Ros, A. F. H., Ferreira, C., Santos, R. S. \& Oliveira, R. F. 2006b. Regulation of immunocompetence by different androgen metabolites in a blenny with alternative reproductive tactics. Journal of Experimental Zoology 305: 986-994.

Ros, A. F. H. \& Oliveira, R. F. 2009. Androgens and immune function in male alternative reproductive morphotypes of the peacock blenny Salaria pavo. Ethology 115: 555-565.

Ross, M. R. 1983. The frequency of nest construction and satellite male behavior in the fallfish minnow. Environmental Biology of Fishes 9: 65-70.

Ruchon, F., Laugier, T. \& Quignard, J. P. 1995. Alternative male reproductive strategies in the peacock blenny. Journal of Fish Biology 47: 826-840.

Sacchi, R., Rubolini, D., Gentilli, A., Pupin, F., Razzetti, E., Scali, S., Galeotti, P. \& Fasola, M. 2007. Morph-specific immunity in male Podarcis muralis. Amphibia Reptilia 28: 408-412.

Sánchez-Guillén, R. A., Martínez-Zamilpa, S. M. J., Jiménez-Cortés, J. G., Forbes, M. R. L. \& Córdoba-Aguilar, A. 2013. Maintenance of polymorphic females: do parasites play a role? Oecologia 171: 105-113.

Sanchez-Guillon, R. A., Hammers, M., Hansson, B., van Gossum, H., Cordero-Rivera, A., Galicia Mendoza, D. I. \& Wellenreuther, M. 2013. Ontogenetic shifts in male mating preference and morph-specific polyandry in a female colour polymorphic insect. $B M C$ Evolutionary Biology 13: 116.

Santos, R. S. 1985a. Estrutura e funcao dos territorios em machos parentais de Blennius sanguinolentus Pallas (Pisces: Blenniidae). Memórias Dos Museu Do Mar Série Zoológica 3: 1-46.

Santos, R. S. 1985b. Parentais e satélites: tácticas alternativas de acasalamento nos machos de Blennius sanguinolentus Pallas (Pisces: Blenniidae). Arquipélago, Série Ciências Da Natureza 6: 119-146.

Santos, R. S. 1995. Anatomy and histology of secondary sexual characters, gonads and liver of the rock-pool blenny (Parablennius sanguinolentus parvicornis) (Pisces: Blenniidae) of the Azores. Arquipélago: Life and Marine Sciences 13A: 21-38.

Santos, R. S. \& Almada, V. (1988) Intraspecific variation in reproductive tactics in males of the rocky intertidal fish Blennius sanguinolentus in Azores. In: Behavioral adaptations to intertidal life (Chellazzi, G. \& Vannini, M., eds.). pp. 421-447. Plenum Press, New York.

Santos, R. S. \& Barreiros, J. P. 1993. The ethogram of Parablennius sanguinolentus Parvicornis (Valenciennes in Cuvier \& Valenciennes, 1836) (Pisces: Blenniidae) from the Azores. Arquipélago: Boletim Da Universidade Dos Açores. Ciências Biológicas e Marinhas 73.

Saraiva, J. L., Gonçalves, D. M. \& Oliveira, R. F. 2010. Environmental modulation of androgen levels and secondary sex characters in two populations of the peacock blenny Salaria pavo. Hormones and Behavior 57: 192-197.

Scalia, S., Isaksen, M. \& Francis, G. W. 1989. Carotenoids of the Arctic charr, Salvelinus alpinus (L.). Journal of Fish Biology 34: 969-970. 
Schunter, C., Vollmer, S. V., Macpherson, E. \& Pascual, M. 2014. Transcriptome analyses and differential gene expression in a non-model fish species with alternative mating tactics. BMC Genomics 15: 167.

Sigurjónsdóttir, H. \& Gunnarsson, K. 1989. Alternative mating tactics of arctic charr, Salvelinus alpinus, in Thingvallavatn, Iceland. Environmental Biology of Fishes 26: 159-176.

Sinervo, B. \& Lively, C. M. 1996. The rock-paper-scissors game and the evolution of alternative male strategies. Nature 380: 240-243.

Sinervo, B. \& Zamudio, K. R. 2001. The evolution of alternative reproductive strategies: fitness differential, heritability, and genetic correlation between the sexes. Journal of Heredity 92: 198-205.

Skau, P. A. \& Folstad, I. 2005. Does immunity regulate ejaculate quality and fertility in humans? Behavioral Ecology 16: 410-416.

Söderhäll, K. (Ed.) (2010) Invertebrate Immunity, Springer Science+Business Media, LLC, Landes Bioscience.

Stearns, S. C. 1992. The evolution of life histories. Oxford University Press, Oxford.

Streilein, J. W. 1996. Peripheral tolerance induction: lessons from immune privileged sites and tissues. Transplantation Proceedings 28: 2066-2070.

Stuglik, M. T., Babik, W., Prokop, Z. \& Radwan, J. 2014. Alternative reproductive tactics and sex-biased gene expression: the study of the bulb mite transcriptome. Ecology and Evolution 4: 623-632.

Svensson, E., Sinervo, B. \& Comendant, T. 2001. Density-dependent competition and selection on immune function in genetic lizard morphs. Proceedings of the National Academy of Sciences, U.S.A. 98: 12561-12565.

Svensson, E. I., McAdam, A. G. \& Sinervo, B. 2009. Intralocus sexual conflict over immune defense, gender load, and sex-specific signaling in a natural lizard population. Evolution 63: 3124-3135.

Taborsky, M. (1994) Sneakers, satellites, and helpers: parasitic and cooperative behavior in fish reproduction. Vol. 23 (Slater, P. J. B., Rosenblatt, J. S., Snowdon, C. T. \& Milinski, M., eds.). pp. 1-100 Advances in the Study of Behavior. Academic Press, New York.

Taborsky, M. (2008) Alternative reproductive tactics in fish. In: Alternative Reproductive Tactics, (Oliveira, R. F., Taborsky, M. \& Brockmann, H. J., eds.). pp. 251-299. Cambridge University Press, Cambridge.

Taborsky, M. \& Brockmann, H. J. (2010) Alternative reproductive tactics and life history phenotypes. In: Animal Behaviour: Evolution and Mechanisms (Kappeler, P., ed.). pp. 537-586. Springer, Berlin.

Taborsky, M., Oliveira, R. F. \& Brockmann, H. J. (2008) The evolution of alternative reproductive tactics: concepts and questions. In: Alternative Reproductive Tactics, (Oliveira, R. F., Taborsky, M. \& Brockmann, H. J., eds.). pp. 1-21. Cambridge University Press, Cambridge.

Tabosrky, M. 2001. The evolution of bourgeois, parasitic, and cooperative reproductive behaviors in fishes. Journal of Heredity 92: 100-110.

Takahashi, Y. \& Watanabe, M. 2010. Female reproductive success is affected by selective male harassment in the damselfly Ischnura senegalensis. Animal Behaviour 79: 211216.

Thomas, F., Reneaud, F. \& Cézilly, F. 1996. Assortative pairing by parasite prevalence in Gammarus insensibilis (Amphipoda): patterns and processes. Animal Behaviour 52: 683-690. 


\section{G. A. LOZANO \& A. F. H. ROS 40}

Tinkle, D. W. 1967. The Life and Demography of the Side-Blotched Lizard, Uta stansburiana. Museum of Zoology, University of Michigan, Ann Arbour.

Todd, B. D. 2007. Parasites lost? An overlooked hypothesis for the evolution of alternative reproductive strategies in amphibians. American Naturalist 170: 793-799.

Travisano, M. \& Shaw, R. G. 2013. Lost in the map. Evolution 67: 305-314.

Uglem, I., Galloway, T. F., Rosenqvist, G. \& Folstad, I. 2001. Male dimorphism, sperm traits and immunology in the corkwing wrasse (Symphodus melops L.). Behavioral Ecology and Sociobiology 50: 511-518.

Uglem, I., Mayer, I. \& Rosenqvist, G. 2002. Variation in plasma steroids and reproductive traits in dimorphic males of corkwing wrasse (Symphodus melops L.). Hormones and Behavior 41: 396-404.

Uglem, I., Rosenqvist, G. \& Wasslavik, H. S. 2000. Phenotypic variation between dimorphic males in corkwing wrasse. Journal of Fish Biology 57: 1-14.

Upton, D. E. \& Murphy, R. W. 1997. Phylogeny of the side-blotched lizards (Phrynosomatidae: Uta) based on mtDNA sequences: support for a midpeninsular seaway in Baja California. Molecular Phylogenetics and Evolution 8: 104-113.

van Gussum, H., Beirinckx, K., Forbes, M. R. \& Sherratt, T. N. 2007. Do current hypotheses explain continental and seasonal variation in female morph frequencies of the damselfly, Nehalennia irene? Biological Journal of the Linnean Society 90: 501-508.

van Rhijn, J. G. 1991. The ruff. Poyser, London.

Verkuil, Y. I., Jukema, J., Gill, J. A., Karlionova, N., Melter, J., Hooijmeijer, J. C. E. W. \& Piersma, T. 2008. Non-breeding fæder ruffs Philomachus pugnax associate according to sex, not morphology. Bird Study 55: 241-246.

Villalba, J. J., Provenza, F. D., Hall, J. O. \& Lisonbee, L. D. 2010. Selection of tannins by sheep in response to gastrointestinal nematode infection. Journal of Animal Science $\mathbf{8 8}$ : 2189-2198.

Vøllestad, L. A. \& L'Abée-Lund, J. H. 1994. Evolution of the life history of Arctic charr Salvelinus alpinus. Evolutionary Ecology 8: 315-327.

Wedekind, C. \& Folstad, I. 1994. Adaptive or nonadaptive immunosuppression by sex hormones? American Naturalist 143: 936-938.

Wellenreuther, M., Svensson, E. I. \& Hansson, B. 2014. Sexual selection and genetic colour polymorphisms in animals. Molecular Ecology 23: 5398-5414.

West-Eberhard, M. J. 1986. Alternative adaptations, speciation, and phylogeny (a review). Proceedings of the National Academy of Sciences, U.S.A. 83: 1388-1392.

Williams, G. C. 1966. Natural selection, the costs of reproduction, and a refinement of Lack's principle. American Naturalist 100: 687-690.

Xu, D. L. \& Wang, D. H. 2010. Fasting suppresses T cell-mediated immunity in female Mongolian gerbils (Meriones unguiculatus). Comparative Biochemistry and Physiology, Part A 155: 25-33.

Zahavi, A. 1975. Mate selection-a selection for a handicap. Journal of Theoretical Biology 53: 205-214.

Zamudio, K. R. \& Chan, L. M. (2008) Alternative reproductive tactics in amphibians. In: Alternative Reproductive Tactics, (Oliveira, R. F., Taborsky, M. \& Brockmann, H. J., eds.). pp. 300-331. Cambridge University Press, Cambridge.

Zera, A. J. \& Denno, R. F. 1997. Physiology and ecology of dispersal polymorphism in insects. Annual Review of Entomology 42: 207-231.

Zera, A. J. \& Harshman, L. G. 2001. The physiology of life history trade-offs in animals. Annual Review of Ecology and Systematics 32: 95-126.

Zuk, M. \& Balenger, S. L. 2014. Behavioral ecology and genomics: new directions, or just a more detailed map? Behavioral Ecology 25: 1277-1282. 